\title{
Modeling Analysis on Propagation of Structure-Borne Vibration Caused by an Indoor Distribution Transformer in a Building and Its Control Method
}

\author{
Junhua Wang ${ }^{1}$, Yi Xu ${ }^{1}$, Kaibin Liang ${ }^{1}$, Qisheng Liu ${ }^{1, *}$, Jiangui $\mathrm{Li}^{2, *}$ and Kaipei Liu ${ }^{1}$ \\ 1 School of Electrical Engineering, Wuhan University, Wuhan 430072, China; junhuawang@whu.edu.cn (J.W.); \\ 15827360565@163.com (Y.X.); Lvsilence@gmail.com (K.L.); kpliu@whu.edu.cn (K.L.) \\ 2 School of Mechanical and Electronic Engineering, Wuhan University of Technology, Wuhan 430070, China \\ * Correspondence: qsliu@hotmail.com (Q.L.); jianguili@whut.edu.cn (J.L.); \\ Tel.: +86-27-6877-6608 (Q.L.); +86-27-8721-8976 (J.L.)
}

Academic Editor: Gino Iannace

Received: 20 March 2017; Accepted: 12 April 2017; Published: 18 April 2017

\begin{abstract}
With the increase of urban population and electricity demand, in order to provide sufficient power to residents, distribution transformers are getting closer to residential buildings, and are even directly placed on the first floor or the basement of buildings due to space limitations. The vibration and noise with low frequency of mainly $50-250 \mathrm{~Hz}$ generated by the distribution transformers spread to rooms through beams, bricks, walls and other building structures, which inevitably damages the living environment. In this paper, through focusing on the frame of buildings, simulation models of the indoor distribution transformer vibrating in the structure field are built, including a two-layer model and a six-layer model. This paper simulates and analyzes the vibration response of the structural system, studies the propagation laws of the structure-borne sound caused by the transformer and quantitatively analyzes the attenuation characteristics of the vibration. Finally the prevention method of the structure-borne noise, called vibration isolation, is introduced and analyzed by the field test to evaluate the noise reduction effect.
\end{abstract}

Keywords: distribution transformer; vibration; structure-borne sound; propagation; vibration isolation

\section{Introduction}

With economic development around the world, the numbers of transformers are increasing as well. At the same time, the noise generated by the transformer has a great impact on residential areas, business centers, factories, subway stations, airports, schools, hospitals and other places. As the urban population and electricity consumption increases, distribution transformers are getting closer and closer to residential areas, and a large number of them even have to be set up in buildings or basements in order to save space.

The main source of the transformer's body noise is from the core and winding vibration [1-6]. The total vibration level on the transformer could be adequately described by the first few harmonics of $100 \mathrm{~Hz}$ [7]. Whereas the airborne sound output of transformers is not tremendously high, the vibration and subsequent structure-borne noise can be extreme. The reflection of solid-borne sound in walls and floors of buildings increases the energy density greatly [8]. For the most part, the transmission loss of the concrete floors is more than sufficient in attenuating airborne sound but structure-borne sound can be carried throughout the floors below for large distances from the transformer location [8], and then through beams, bricks, and walls to the rooms, thus resulting in more and more complaints from residents. The structure-borne sound and airborne sound transmission paths are shown in Figure 1. In view of this problem, it is difficult to adopt traditional sound insulation, muffler or sound control 
measures to achieve the desired results. Building engineers and consultants address airborne noise problems more effectively and confidently than structure-borne noise problems [9].

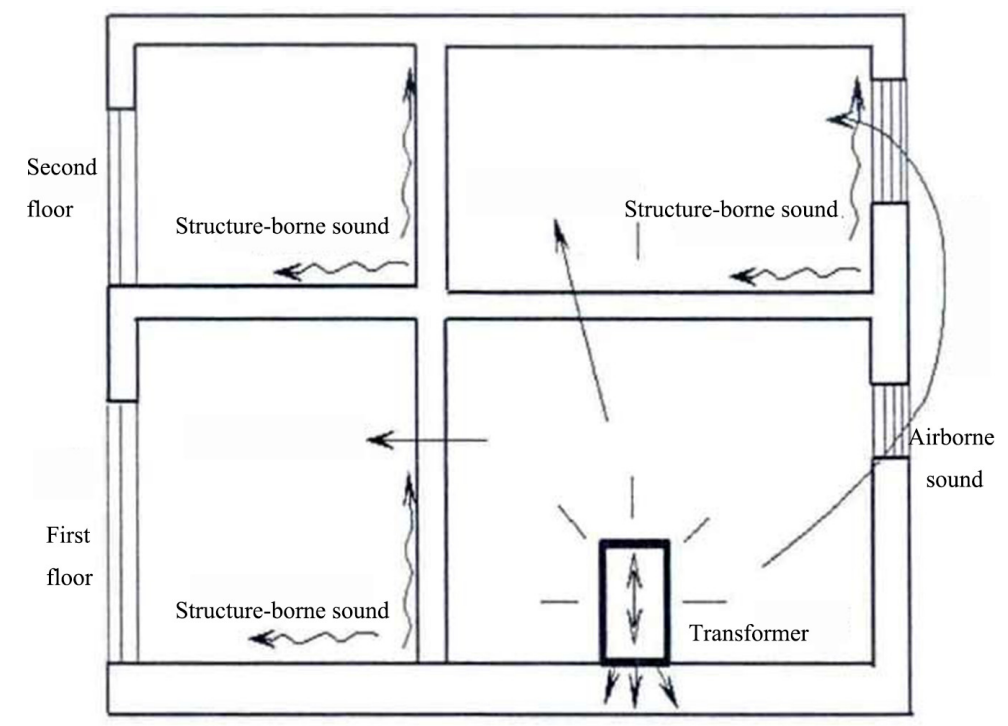

Figure 1. The structure-borne sound and airborne sound caused by the indoor transformer transmission paths.

In order to predict and measure the structure-borne sound in buildings, a series of methods and techniques have been established. Statistical energy analysis (SEA) is a technique ideally suited for the study of sound and vibration transmission through complex structures [10]. Craik and Yamazaki et al. [11,12] examined the structural coupling and used SEA models to learn the vibration and sound propagating paths. However, statistical energy analysis is unreliable at low frequencies due to the statistical uncertainties that occur when there are few resonant modes in each of the elements or subsystems [10]. Finite element models do not suffer from these limitations at low frequencies and can be used to model such systems "exactly". Steel and Craik [10] used a finite element model to carry out "numerical experiments" to show the relationship between the properties of subsystems and the coupling between them. Toyoda and Takahashi [13] used the finite-difference time-domain method which is investigated as a new prediction method for architectural structure-borne sound.

In addition, Mandal et al. [14] used techniques of Fourier transform and finite difference approximation to formulate vibration power flow model. Magalhaes [15] predicted the sound power radiated by a floating floor system using a model that used fluid-structure interaction and the Jinc function approach. Magalhaes and Ferguson [16] analytically developed the three-dimensional Component Mode Synthesis method and used it on studying sound transmission between coupled volumes. Sanayei et al. [17] developed an impedance model to study ground-borne vibrations caused by passing traffic in the test building. Moorhouse et al. [18] developed a method for characterizing building-mounted wind turbines (BMWTs) as sources of structure-borne sound and derived a methodology for prediction of structure-borne sound and vibration inside attached dwellings.

Although there has been a development of methods of prediction and measurement of structure-borne sound, there still remains a shortfall in methods of predicting noise from vibrating machines in contact with building elements, which transmit vibrations and radiate sound [3], especially the specific study on the distribution transformer's vibration and noise in the building.

This paper focuses on frame structure, and builds simulation models of the indoor distribution transformer's vibration in the structure field. This paper firstly builds two-layer and six-layer equivalent models, then simulates and analyzes the vibration response of the structural system to study the propagation laws and attenuation characteristics of the vibration caused by the transformer, and finally proposes the prevention method and carries out the field test. 
2. Analysis on the Propagation Mechanism of Vibration of Distribution Transformer in Building Structure

The structure of the building can be seen as a combination of basic elements such as plates (walls, floors) and rods (beams, columns). When an element is excited by the force, the vibration will propagate in the form of an elastic wave along the element. Coming to the next element, a part of the elastic wave enters the adjacent element through the interface, while the other part reflects back against the interface, in which way the wave propagates to the far areas making each component vibrate correspondingly and radiates the reproduction air noise to the surrounding space. That is the structure-borne sound. When the sound waves propagate in the solid medium, the mass point of the medium is displaced, the medium is deformed, and there is a force between different parts of the medium which affects each other, called strain and stress. This is the basic principle of the propagation of vibration in solids. In the following, the strain and stress are analyzed, then the acoustic equation is performed so as to analyze the transmission mechanism of the transformer's vibration in the building structure as the theoretical basis of simulation.

\subsection{Strain Analysis in Solid}

The study point of the solid is named point $\mathrm{A}$, and its coordinate is $(x, y, z)$. This point will produce a certain displacement in space when subjected to the external force. Assume that the displacement components corresponding to the three directions in space are respectively $\xi, \eta$, and $\zeta$. Assume that the coordinate of its adjacent point $C$ is $(x+d x, y+d y, z+d z)$, and the corresponding displacements are $\xi+d \xi, \eta+d \eta$, and $\zeta+d \zeta$. The Taylor equation is used to decompose it, then the displacement difference between $\mathrm{A}$ and $\mathrm{C}$ point can be obtained as follows:

$$
\left.\begin{array}{l}
d \xi=\frac{\partial \xi}{\partial x} d x+\frac{\partial \xi}{\partial y} d y+\frac{\partial \xi}{\partial z} d z \\
d \eta=\frac{\partial \eta}{\partial x} d x+\frac{\partial \eta}{\partial y} d y+\frac{\partial \eta}{\partial z} d z \\
d \zeta=\frac{\partial \zeta}{\partial x} d x+\frac{\partial \zeta}{\partial y} d y+\frac{\partial \zeta}{\partial z} d z
\end{array}\right\}
$$

It can be seen that the deformation of the object can be expressed by the following formula:

$$
\left|\begin{array}{lll}
\frac{\partial \xi}{\partial x} & \frac{\partial \xi}{\partial y} & \frac{\partial \xi}{\partial z} \\
\frac{\partial \eta}{\partial x} & \frac{\partial \eta}{\partial y} & \frac{\partial \eta}{\partial z} \\
\frac{\partial \zeta}{\partial x} & \frac{\partial \zeta}{\partial y} & \frac{\partial \zeta}{\partial z}
\end{array}\right|
$$

The Figure 2 is a simplified diagram of the object deformation. The ABCD in the figure represents the solid model before being subjected to the force, and $\mathrm{A}^{\prime} \mathrm{B}^{\prime} \mathrm{C}^{\prime} \mathrm{D}^{\prime}$ is the solid model that produces the deformation after subjected to the force.

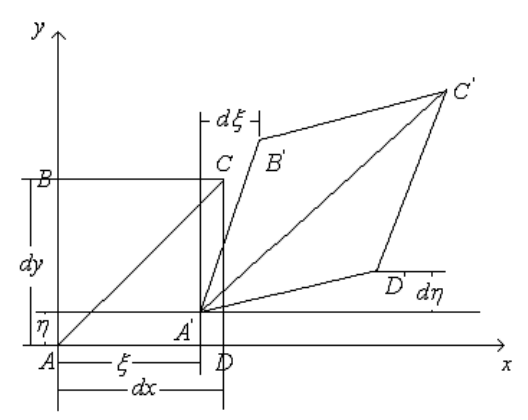

Figure 2. Two-dimensional deformation of the object. 


\subsection{Stress Analysis in Solid}

A complete object can be seen as a combination of many small parts, and each part interacts with the others. Take one part, $d V$, for analysis. When it is subjected to external stress, the body part will bear the effect of other bodies around it. The force includes a normal stress perpendicular to the surface of the action and a shear stress parallel to it. Figure 3 shows the stress analysis of the small body element.

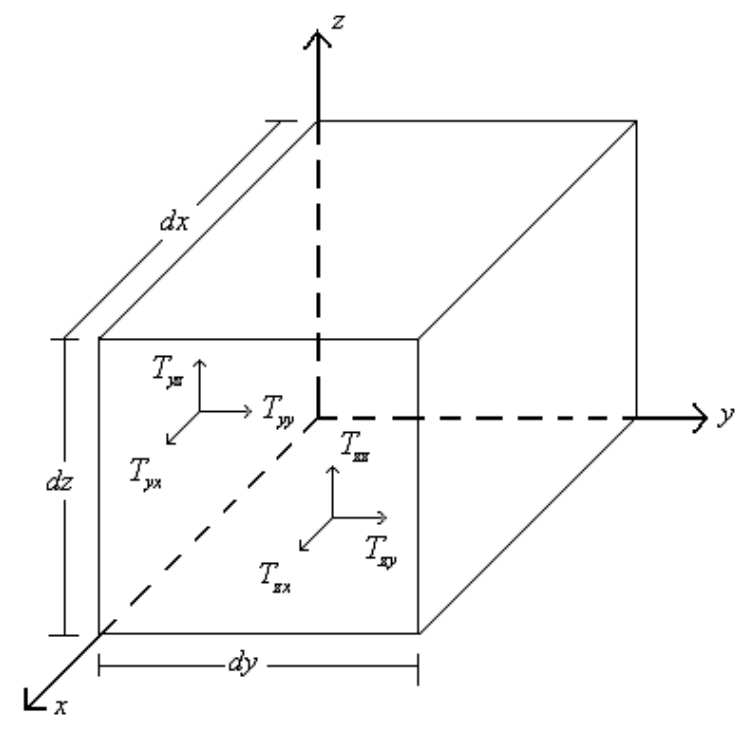

Figure 3. Stress analysis of small body element.

The stress of the small body element can be expressed by the following formula:

$$
\left|\begin{array}{lll}
T_{x x} & T_{x y} & T_{x z} \\
T_{y x} & T_{y y} & T_{y z} \\
T_{z x} & T_{z y} & T_{z z}
\end{array}\right|
$$

where $T_{x x}$ represents the stress acting on the $x$-plane and pointing to the $x$-axis, $T_{x y}$ represents the stress acting on the $x$-plane and pointing to the $y$-axis, and the other quantities are similarly labeled. $T_{i j}(i, j=x, y, z)$ represents the stress in all directions. If $i$ and $j$ are equal, this represents the normal stress, if not, this represents the shear stress. In practice, there is a symmetry between these quantities, that is to say, $T_{i j}$ and $T_{j i}$ have the same size in fact. Therefore, only six quantities among the nine need to be known for the stress in the solid to be uniquely determined.

\subsection{Acoustic Equation in Solid}

Analyze the movement of the small body element in the $x$ direction separately in Figure 3. A similar analysis can be performed for the $y$ and $z$ direction. The external force that the small body element suffers in $x$ direction can be divided into a normal stress perpendicular to the $x$-axis and a tangential stress perpendicular to the $y$-axis and $z$-axis.

The force in the $x$ direction acting on the surface perpendicular to the $x$-axis is:

$$
F_{x}^{\prime}=\left(T_{x x}+\frac{\partial T_{x x}}{\partial x} d x-T_{x x}\right) d y d z
$$

The force in the $x$ direction acting on the surface perpendicular to the $y$-axis is:

$$
F_{x}^{\prime \prime}=\left(T_{y x}+\frac{\partial T_{y x}}{\partial x} d x-T_{y x}\right) d x d z
$$


The force in the $x$ direction acting on the surface perpendicular to the $z$-axis is:

$$
F_{x}^{\prime \prime \prime}=\left(T_{z x}+\frac{\partial T_{z x}}{\partial x} d x-T_{z x}\right) d x d y
$$

The sum of the three stresses is the stress in the $x$ direction:

$$
F_{x}=\left(\frac{\partial T_{x x}}{\partial x}+\frac{\partial T_{y x}}{\partial y}+\frac{\partial T_{z x}}{\partial z}\right) d x d y d z
$$

According to Newton's second law, Equation (8) represents the equation of motion in $x, y$, and $z$ direction, where $\rho$ is the density of the substance.

$$
\left.\begin{array}{l}
\rho \frac{\partial^{2} \xi}{\partial t^{2}}=\frac{\partial T_{x x}}{\partial x}+\frac{\partial T_{y x}}{\partial y}+\frac{\partial T_{z x}}{\partial z} \\
\rho \frac{\partial^{2} \eta}{\partial t^{2}}=\frac{\partial T_{x y}}{\partial x}+\frac{\partial T_{y y}}{\partial y}+\frac{\partial T_{z y}}{\partial z} \\
\rho \frac{\partial^{2} \zeta}{\partial t^{2}}=\frac{\partial T_{x z}}{\partial x}+\frac{\partial T_{y z}}{\partial y}+\frac{\partial T_{z z}}{\partial z}
\end{array}\right\}
$$

Since the performance values of the object measured in different directions are exactly the same, according to the generalized Hooke's law of isotropic media and combined with Equation (1), the following can be obtained:

$$
\left.\begin{array}{r}
\rho \frac{\partial^{2} \xi}{\partial^{2}}=(\lambda+\mu) \frac{\partial \Delta}{\partial x}+\mu \nabla^{2} \xi \\
\rho \frac{\partial^{2} \eta}{\partial t^{2}}=(\lambda+\mu) \frac{\partial \Delta}{\partial y}+\mu \nabla^{2} \eta \\
\rho \frac{\partial^{2} \zeta}{\partial t^{2}}=(\lambda+\mu) \frac{\partial \Delta}{\partial z}+\mu \nabla^{2} \zeta
\end{array}\right\}
$$

where $\Delta=\frac{\partial \xi}{\partial x}+\frac{\partial \eta}{\partial y}+\frac{\partial \zeta}{\partial z}, \nabla^{2}=\frac{\partial^{2}}{\partial x^{2}}+\frac{\partial^{2}}{\partial y^{2}}+\frac{\partial^{2}}{\partial z^{2}}$, and $\lambda, \mu$ are the Lame coefficient.

Take $\vec{s}=\xi \vec{i}+\eta \vec{j}+\zeta \vec{k}$ to represent the particle displacement, Equation (9) can be written in vector form:

$$
\rho \frac{\partial^{2} \vec{s}}{\partial t^{2}}=(\lambda+\mu) \operatorname{grad} \Delta+\mu \nabla^{2} \vec{s}
$$

\section{Simulation Analysis}

In this part, the finite element simulation models are built to study the indoor distribution transformer's vibration in the building structure field. We use the finite element method to carry out the simulation.

\subsection{Model Building}

In order to analyze the influence of indoor distribution transformers' vibration on the internal structure of the building, and study the propagation law of the vibration in the solid structure, the following two-layer and six-layer models of the structure-borne sound field were built. In these models, the transformer is equivalent to a rectangular box for processing, and the value of the excitation source is the result of test on site.

The model is a typical residence and the size of the frame column of Figure 4 is $0.8 \mathrm{~m} \times 0.8 \mathrm{~m}$. The horizontal separation between columns is $6 \mathrm{~m}$, while the longitudinal distance is $4 \mathrm{~m}$. The total area of the basement is $560 \mathrm{~m}^{2}$. 


\begin{tabular}{|c|c|c|c|c|c|c|}
\hline 口 & ㅁ & 口 & ㅁ & ㅁ & ㅁ & 口 \\
\hline 口 & 므 & 口 & 口 & ㅁ & ㅁ & 口 \\
\hline 口 & 口 & 口 & 口 & ㅁ & 口 & 口 \\
\hline [ & 口 & 口 & 口 & ㅁ & 므 & 口 \\
\hline
\end{tabular}

Figure 4. Frame structure of the basement.

Each layer of the model includes four households as in the Figure 5. The red boxes indicate the position of the elevator and the door, while the blue one represents households, including three rooms. The specific structure of rooms are not discussed in detail in order to simplify the problem.

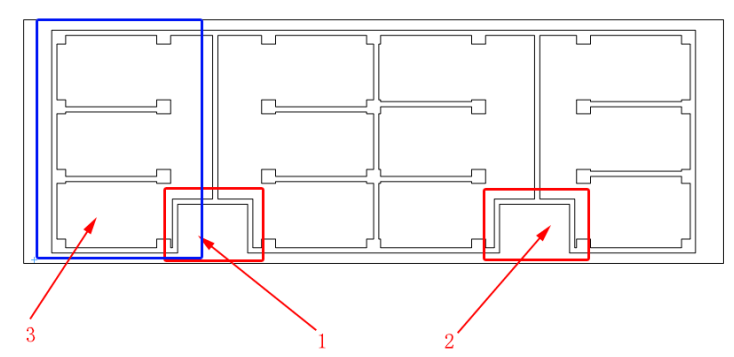

Figure 5. Schematic of the residence floor. Red box 1 and red box 2 represent the positions of the elevator and the door; blue box 3 represent a household, including three rooms.

The two-layer simple model of Figure 6 whose upper floor is not enclosed is built to explore the propagation law of the transformer's vibration indoors. As for a specific building structure, the corresponding six-layer model is built on the basis of the two-layer model as in Figure 7.

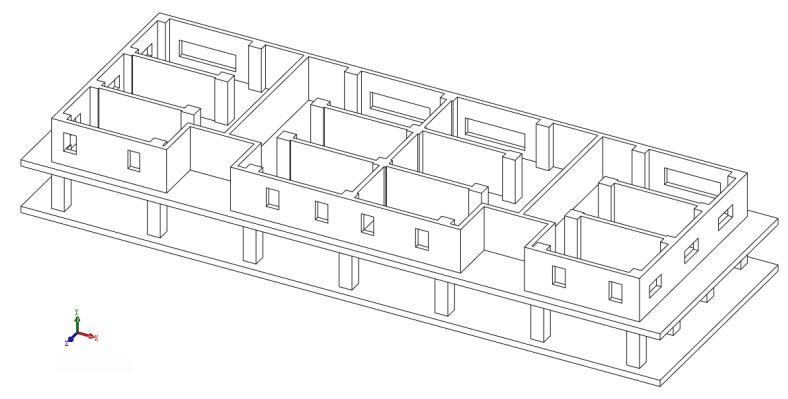

Figure 6. Three-dimensional structure diagram of the two-layer residence model.

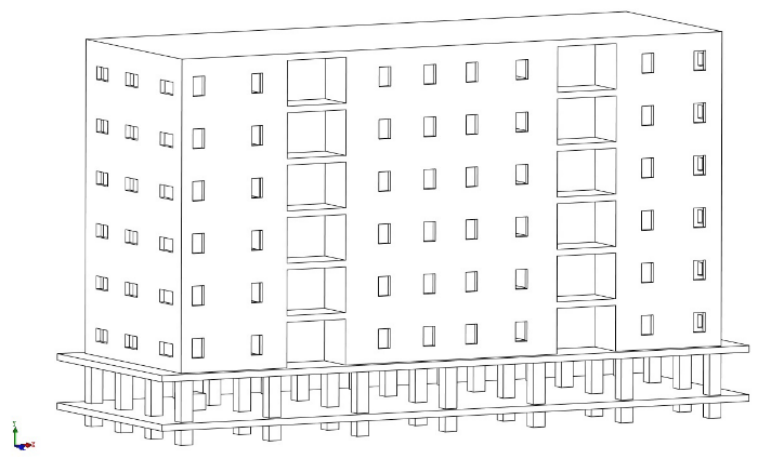

Figure 7. Six-layer building model. 


\subsection{Placement of the Transformer and Probes}

The placement of the transformer is critical to the transmission of vibration. In practice, the transformer is usually placed at the basement. Taking the symmetry of the basement structure into account, only six typical areas in Figure 8 need to be analyzed.

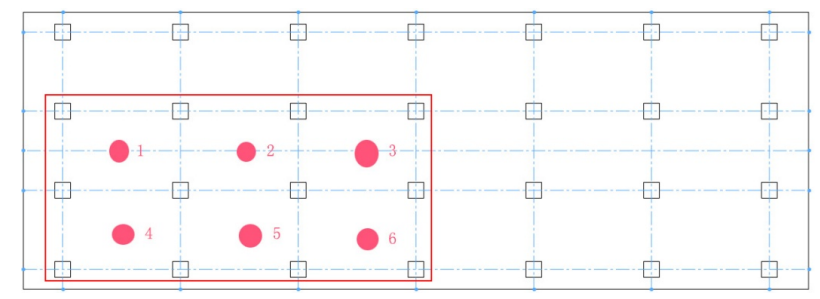

Figure 8. The placement of the transformer. The six red dots represent the six positions where the transformer is placed.

For the two-layer model, there are 20 probes set in Figure 9. The vibration response spectrum and displacement nephogram of each point can be extracted after simulation. Monitored points are generally located near the windows or the walls in that furniture such as tables, chairs and beds are usually placed closer to the wall, rather than the central area of the room, which meets people's living habits.

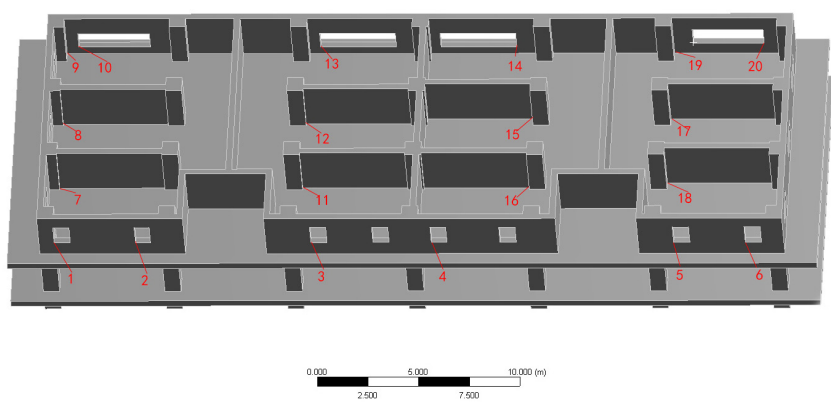

Figure 9. The indoor monitoring points.

In the six-layer model, the transformer is placed in the same position as in the two-layer model. However, the probes are mainly set outside as in Figure 10, because for the six-layer model, it is inconvenient and insignificantly meaningful to study the propagation law indoors. All the monitoring points are arranged besides the window to study the vibration's propagation law from three directions.

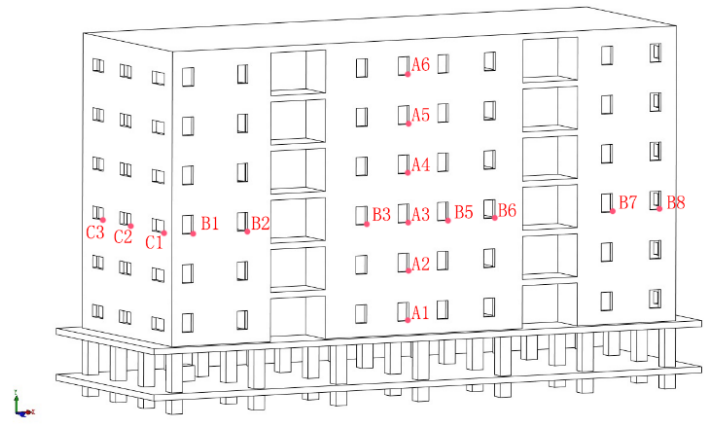

Figure 10. The location of the external monitoring points in six-layer model. A1-A6 are six monitoring points of vertical direction of the building; B1-B8 are eight monitoring points of horizontal direction of the building; $\mathrm{C} 1-\mathrm{C} 3$ are three monitoring points of the longitudinal direction of the building. 


\subsection{Simulation Results}

\subsubsection{Two-Layer Model}

The two-layer model is built to study the structure-borne sound's propagation law indoors and the vibration strength distributions when vibration propagates along the beam, brick, and wall units.

Apply the excitation quantity as measured on the field site to the model as shown in Figure 11 which shows the vibration spectrum of the transformer. Although the vibration of the transformer will be different under different working conditions, for the simulation analysis, considering the vibration propagation law of the transformer, the intensity of the vibration does not affect its propagation law. In the actual measured vibration values given in Figure 11, we use the vibration curve under no-load condition. The specific parameters of Power Spectral Density (PSD) acceleration which applies to the equivalent rectangular box's upper surface are shown in the Figure 12.

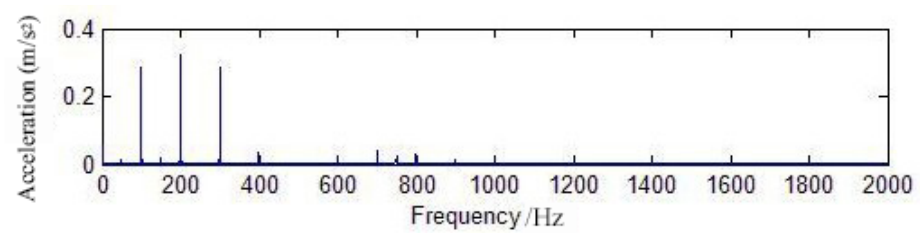

(a)

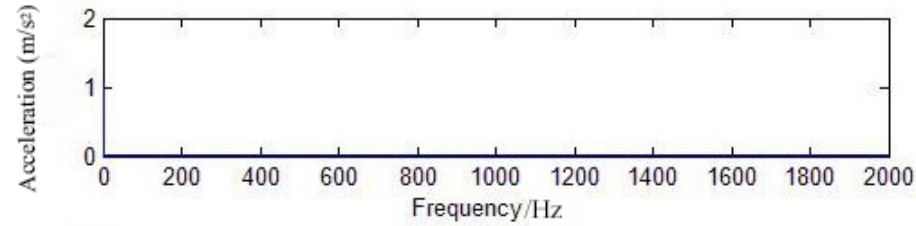

(b)

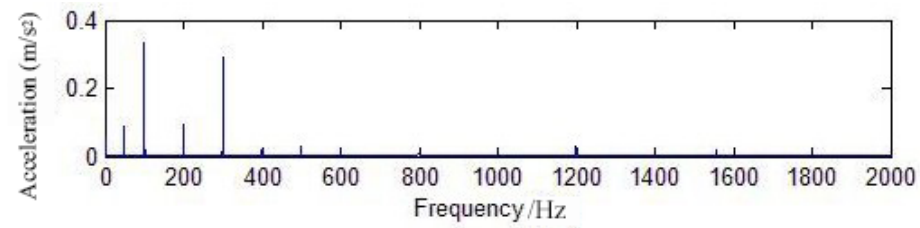

(c)

Figure 11. Acceleration spectrum of the transformer's vibration: (a) No-load; (b) Short-circuit; (c) Load.

Take the transformer that is placed at position \#3 as an example to study the propagation law. The unit in Figure 13 is meter. In the nephogram, the displacement is used as an indicator, and the blue region indicates the vibration intensity is relatively low, while the red region indicates more severely-affected areas. The displacement is the sum of the components of different frequencies. As is shown in Figure 13, the vibration propagates upward along columns and beams. In the process of transmission, the floor structure of the house is relatively stable and less affected by the vibration, but the amplitude of the surrounding walls is relatively large. The amplitude of the vibration reaches the peak at the wall edge on sides of the $X$-direction of the house, and the vibration amplitude of the four walls along the longitudinal direction of the house (Z-direction in the Figure 13) is also large. Structure-borne sound wave will be attenuated when propagating in the building structure, and the amount of attenuation when propagating to the floor is greater than that to the wall. Location \#3 is at the center, where the impact of the transformer as a vibration source on the entire house structure is significant. 


\begin{tabular}{|c|l|l|}
\hline & Frequency $[\mathrm{Hz}]$ & Acceleration $\left[\left(\mathrm{m} / \mathrm{s}^{2}\right)^{2} / \mathrm{Hz}\right]$ \\
\hline 1 & 50 & $5 \times 10^{-2}$ \\
\hline 2 & 100 & 0.3 \\
\hline 3 & 200 & 0.35 \\
\hline 4 & 300 & 0.3 \\
\hline 5 & 400 & $3 \times 10^{-2}$ \\
\hline 6 & 700 & $3 \times 10^{-2}$ \\
\hline 7 & 750 & $2 \times 10^{-2}$ \\
\hline 8 & 800 & $5 \times 10^{-2}$ \\
\hline
\end{tabular}

Figure 12. Specific parameters of Power Spectral Density (PSD) acceleration.

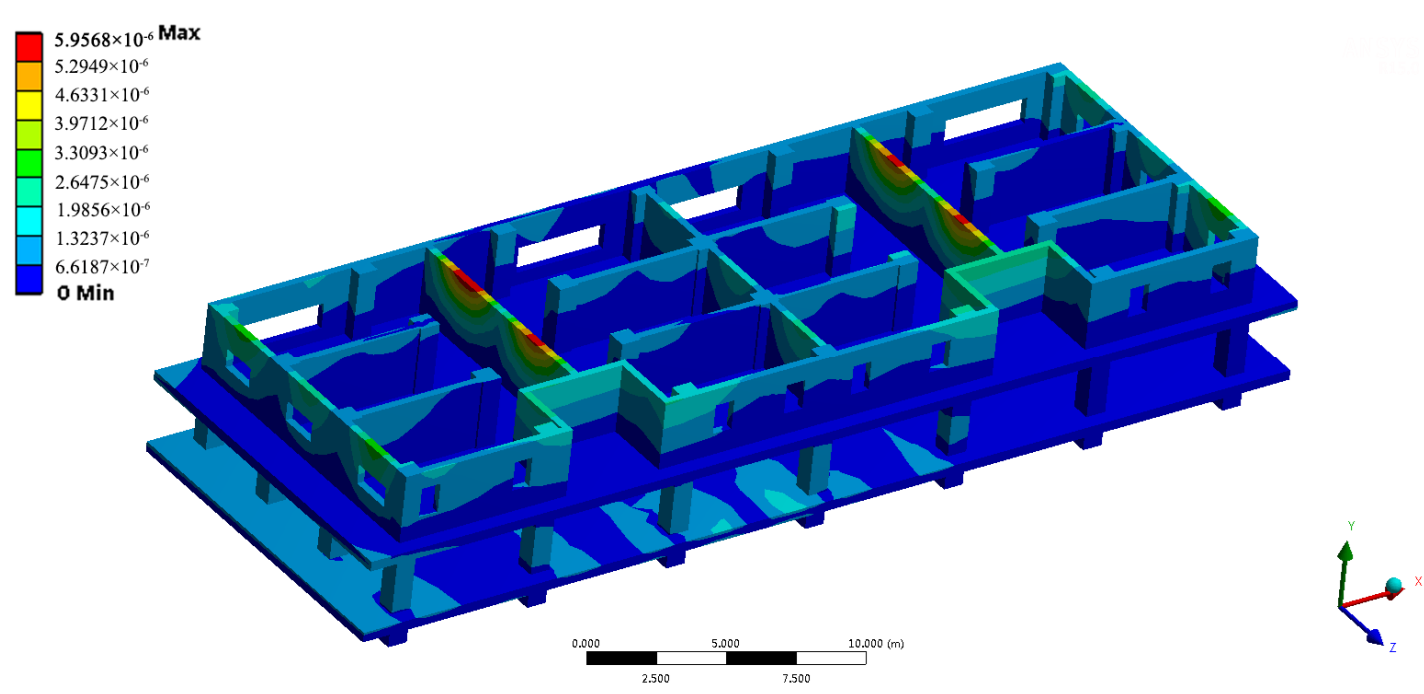

Figure 13. Displacement nephogram in two-layer model when the transformer is at position \#3.

In detail, we can further obtain the response spectrum of the typical monitoring point. We use the frequency-acceleration curve to learn more about the vibration. In the range of $800 \mathrm{~Hz}$, the response spectrum of vibration at point 1 is shown in Figure 14. The monitoring value can be shown in $X, Y$, $Z$ directions.

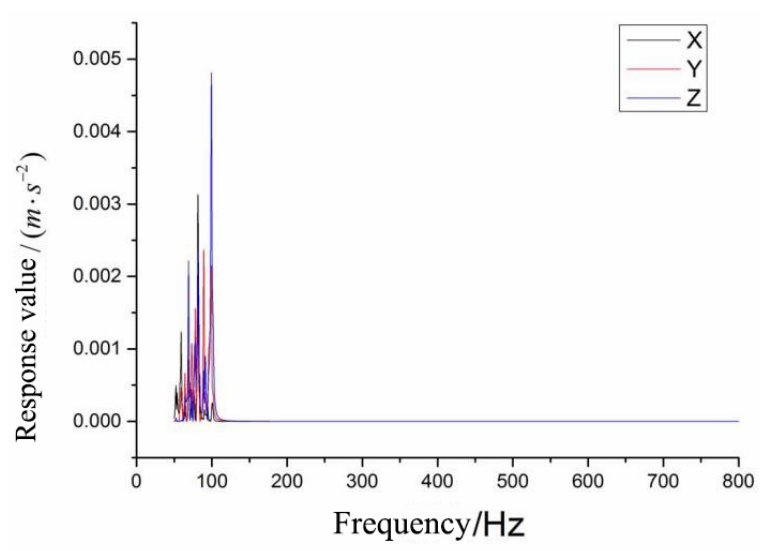

Figure 14. The transformer is at position \#3, and the response spectrum of monitoring point No. 1 in the two-layer model. 
The response spectrum is mainly around $100 \mathrm{~Hz}$, and the response spectrum at high frequencies can be negligible. In order to dramatically display the result, the data should be filtered, only considering the value within $150 \mathrm{~Hz}$, and adjusting the $X$-coordinate. The corresponding response spectrum curve is shown in Figure 15.

Considering that the vibrations in the three directions are almost of the same magnitude, and in practice, the vibration of the transformer is mainly up and down [19], when the excitation is applied, only the vibration in the $Y$ direction will be analyzed. The transformer's position remains unchanged, and the response curve of 1-6 test points at the front side is shown in Figure 16.

It can be seen that the vibrations of point 2 and point 5 are relatively stronger than other points, which coincides with the result in the displacement nephogram. From Figure 16, we can find that in $X$-coordinate, with the distance to the transformer increasing, the amplitude of vibration has a decreasing trend, but this rule is not quite obvious.

The points 3, 11, 12 and 13 of the $Z$ direction are examined, and their vibration intensities are compared as shown in Figure 17, demonstrating that the vibration of the edge is stronger than that of the center. This is because the stability of the intermediate structure is higher, and the vibration will be transmitted to the edge.

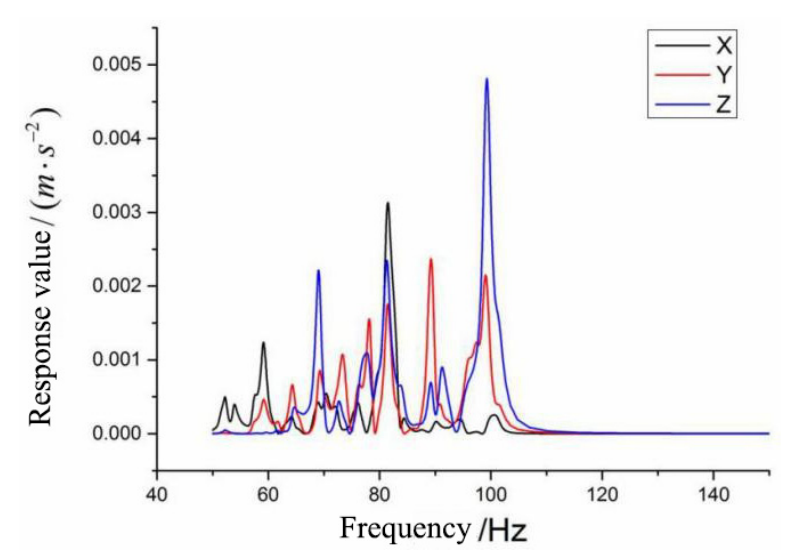

Figure 15. Adjusted response spectrum.

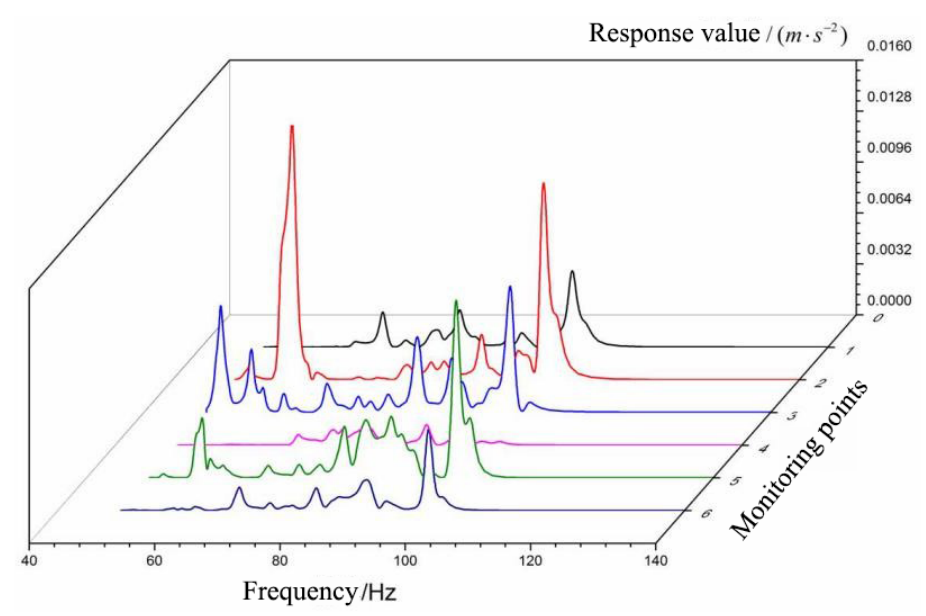

Figure 16. Monitoring data of six monitoring points of the $X$ direction in the front of the house. 


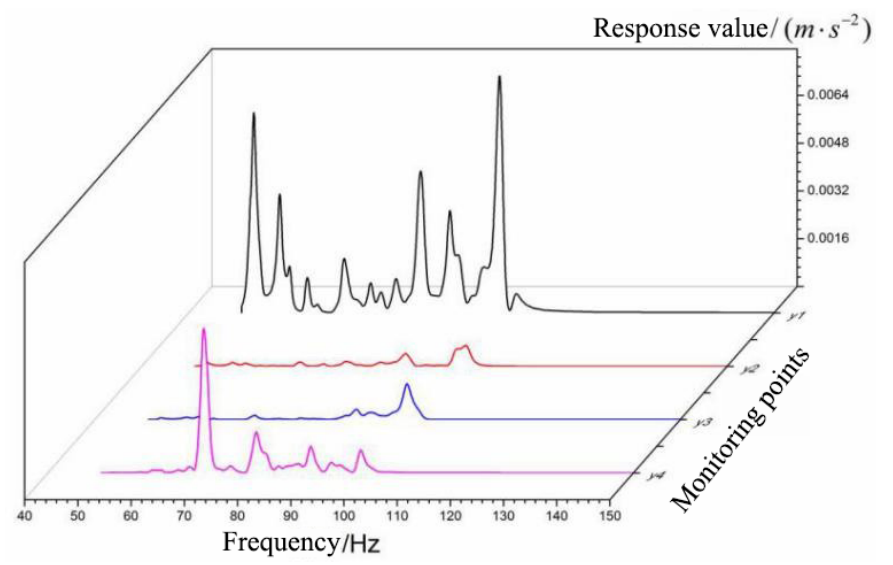

Figure 17. Monitoring data of four monitoring points of the $Z$ direction in the house.

Then, we compare the vibration propagation of the transformer in different positions. When the position of the transformer changes, the transmission of the vibration will show different characteristics. The displacement nephograms of the transformer at the 1,2,4,5, and 6 positions are successively listed below from Figures 18-22. The unit in figures is meter.

As is shown in the above nephograms, the effect of transformer's vibration on the structure of the two-layer model will be different due to different placement of the transformer under the same excitation. From Figures 13 and 18, Figures 19-22, it is not difficult to find that the position of the maximum amplitude has changed. When the transformer is successively placed at position $\# 1, \# 2$, and \#3, the influence of the vibration on the wall of the Z-direction at the center position is gradually increasing. When the transformer is placed at position \#1, the displacement of the wall of the Z-direction at the center position is about $0-7.8758 \times 10^{-7} \mathrm{~m}$, while it is $5.9859 \times 10^{-7}-1.7958 \times 10^{-6} \mathrm{~m}$ when the transformer is placed at position \#2, and 0-1.9856 $\times 10^{-6} \mathrm{~m}$ when the transformer is placed at position \#3. Through the simulation nephogram, when transformer is at position \#3, which is just in the middle of the model, the impact of vibration on the house is the most extensive. The area achieves the maximum displacement $5.9568 \times 10^{-6} \mathrm{~m}$ is relatively larger.

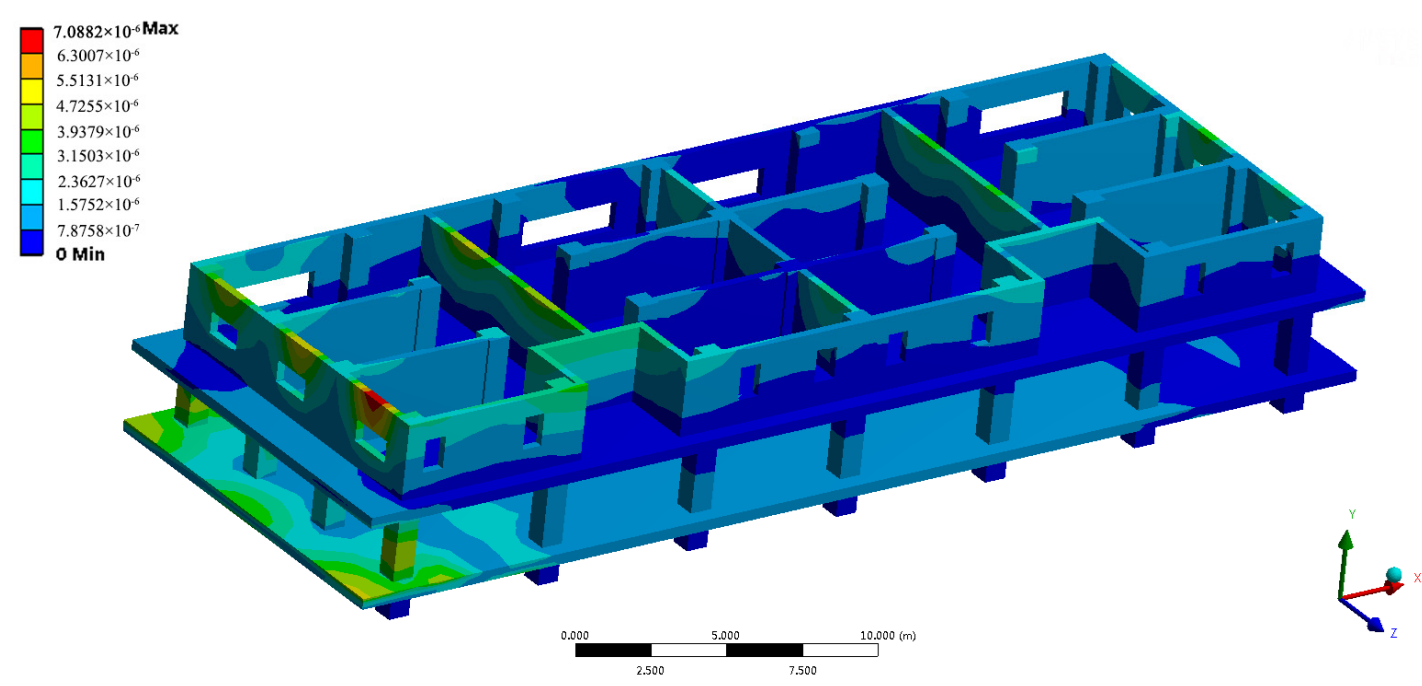

Figure 18. Displacement nephogram in two-layer model when the transformer is at position \#1. 


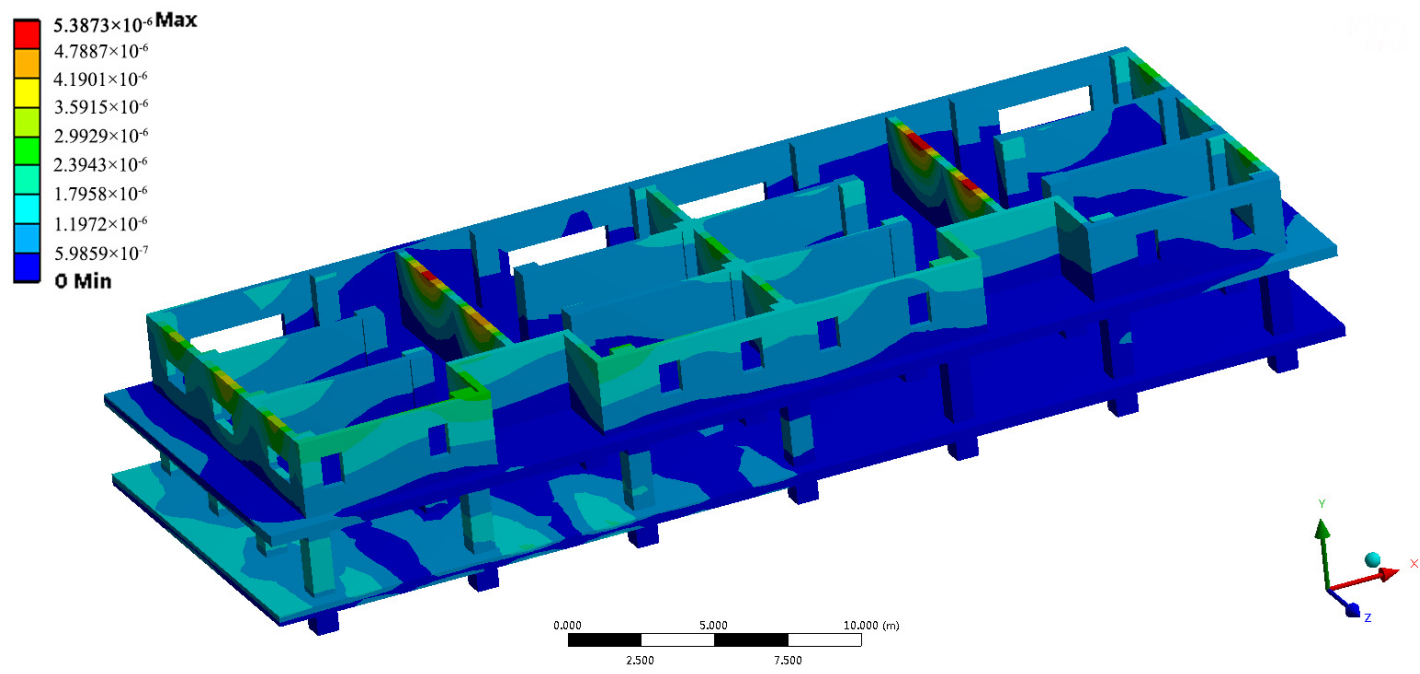

Figure 19. Displacement nephogram in two-layer model when the transformer is at position \#2.

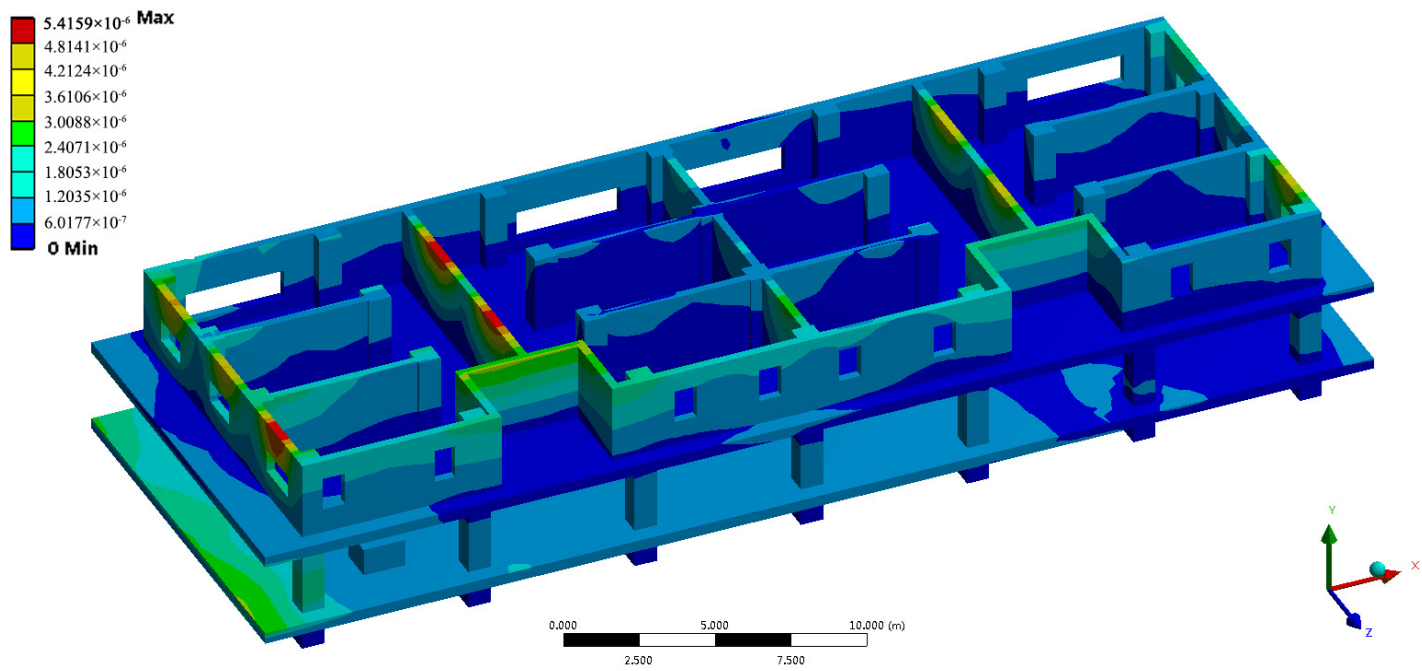

Figure 20. Displacement nephogram in two-layer model when the transformer is at position \#4.

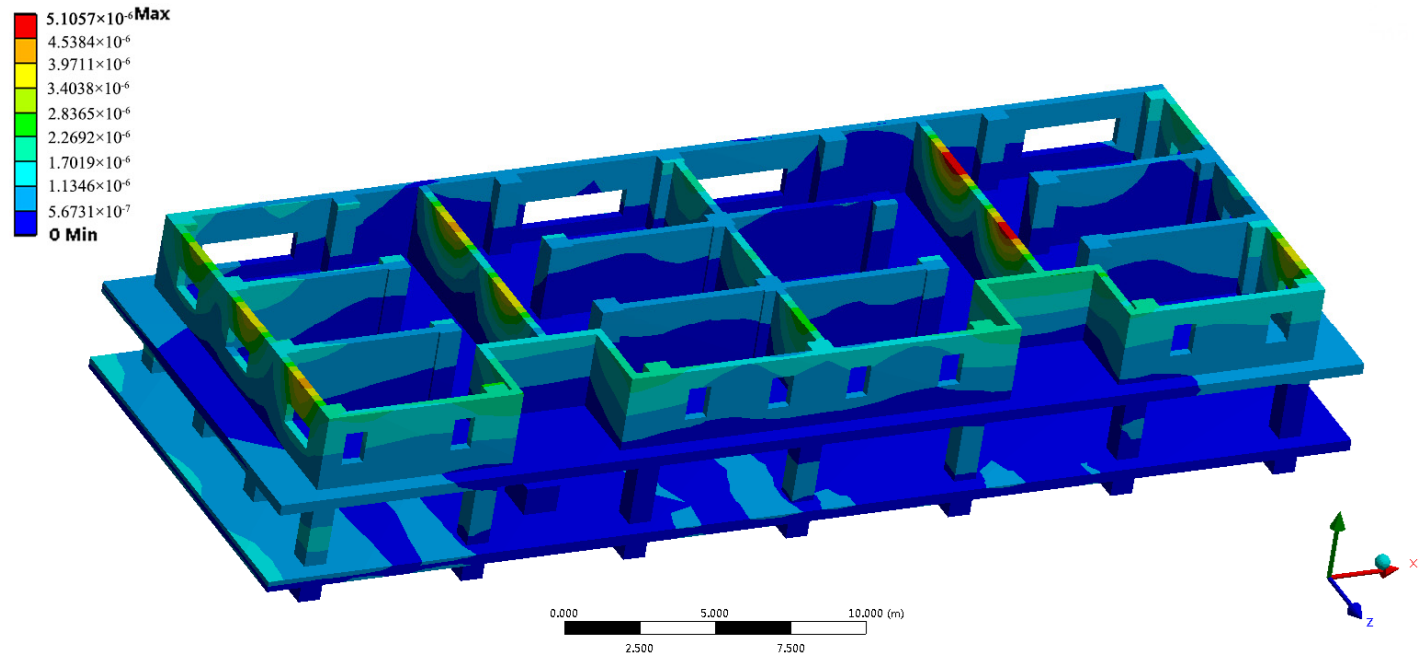

Figure 21. Displacement nephogram in two-layer model when the transformer is at position \#5. 


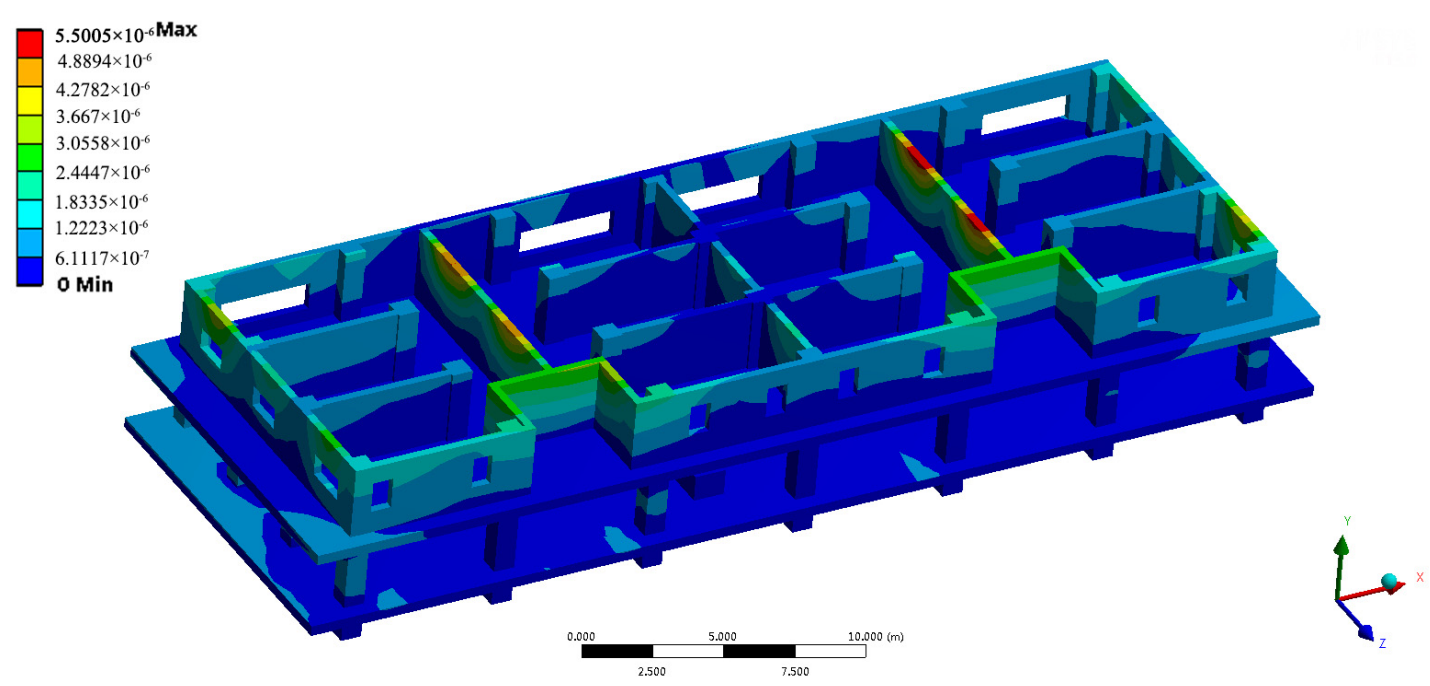

Figure 22. Displacement nephogram in two-layer model when the transformer is at position \#6.

When the position of the transformer changes, the parameters measured at the monitoring points will change accordingly. Choose three typical monitoring points for analysis. Point 1 is located at the front left side of the house; point 12 is located at the middle of the house; point 20 is located on the diagonal line with point 1 and in simulation, is always the farthest point away from the vibration source.

From Figure 23, the vibration intensity of point 1 reaches the maximum when the transformer is set at position \#1, even larger than that when transformer is at position \#4. Besides, when the transformer is at positions \#2 and \#5, the vibration intensity of the high-frequency component cannot be neglected compared with the other cases. Further examined vibration data within $150 \mathrm{~Hz}$ are shown in Figure 24.

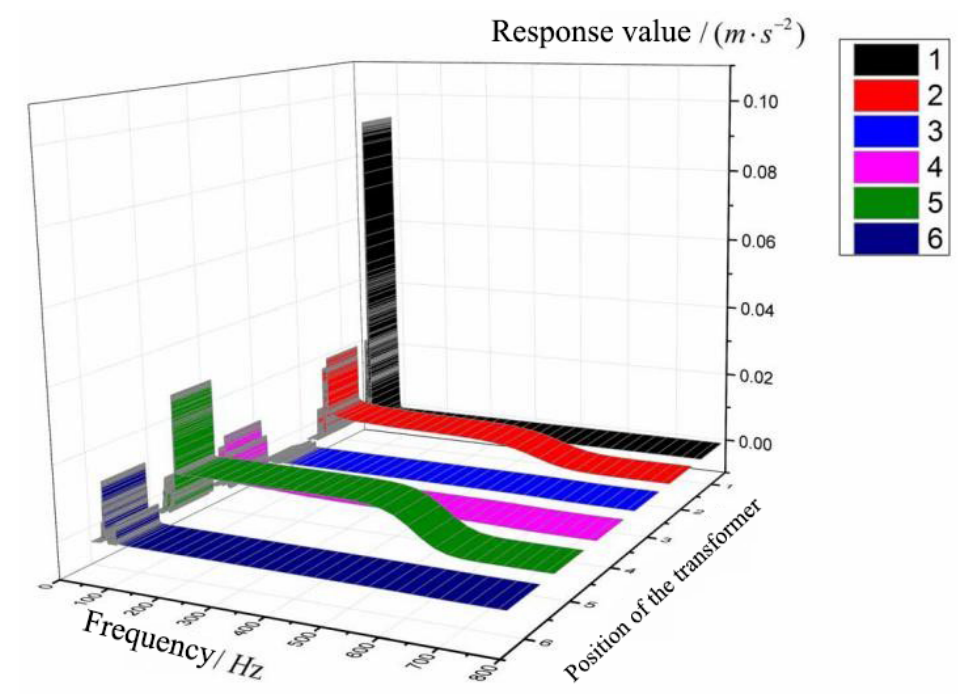

Figure 23. Vibration data of the point 1 when the transformer is at different positions. 


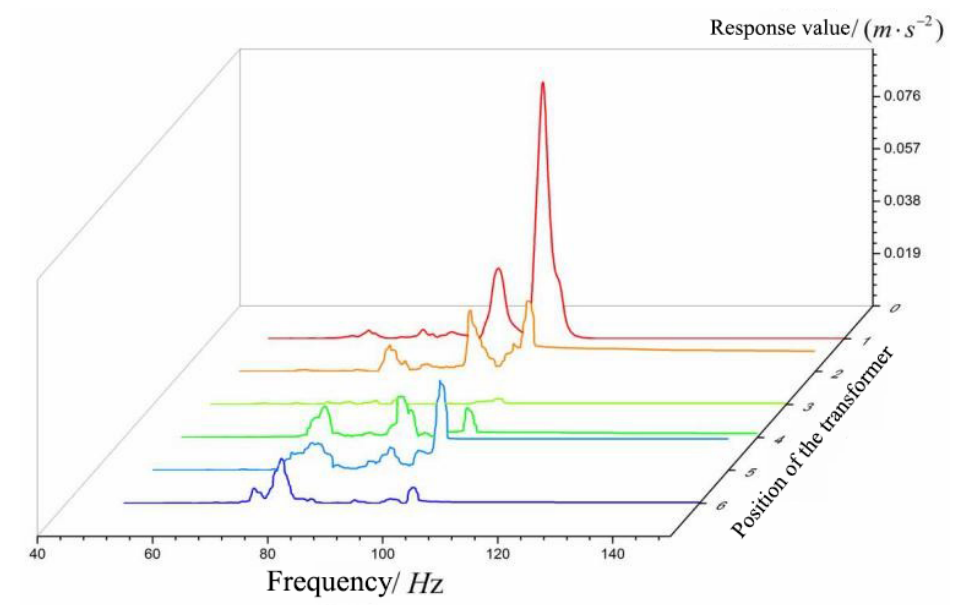

Figure 24. Vibration data of the point 1 when the transformer is at different positions (within $150 \mathrm{~Hz}$ ).

As for the monitoring point 12 and 20 vibration, the results are respectively shown in Figures 25 and 26.

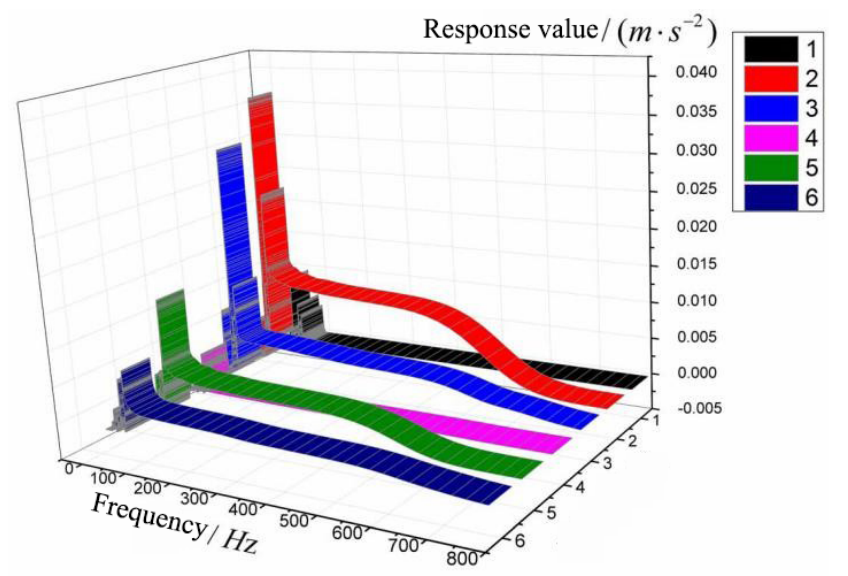

Figure 25. Vibration data of the point 12 when the transformer is at different positions.

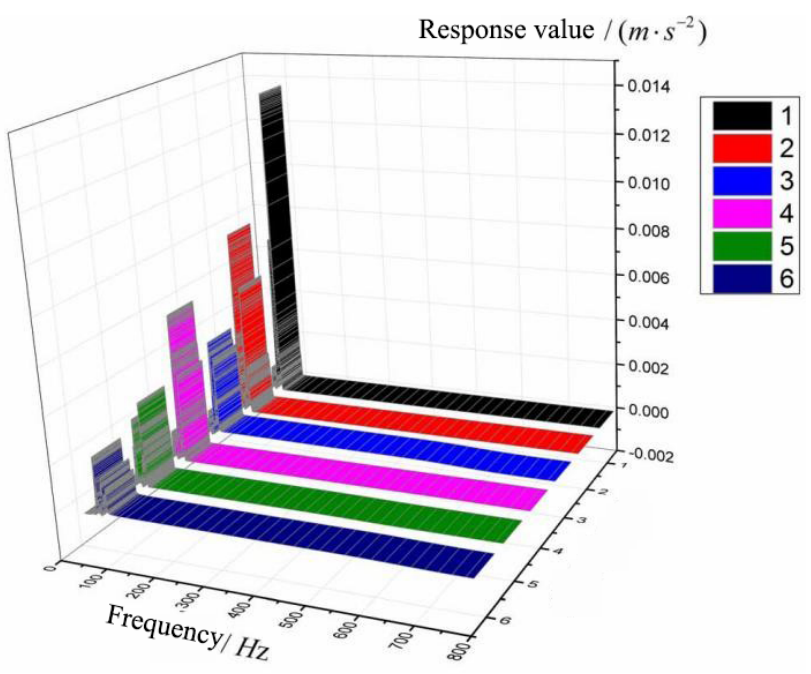

Figure 26. Vibration data of the point 20 when the transformer is at different positions. 
As is shown in Figures 23-26, the placement of the transformer has great impact on the vibration propagation. When the transformer is located at the central location, it impacts most on the structure that is right above it and less on the surrounding structure, but still cannot be ignored. For example, when the transformer is at positions \#2 and \#3, the vibration intensity of the monitoring point 12 is the strongest. When the transformer is located at one side edge of the house, it impacts more on all surrounding structures, but much less on the central position. For example, when the transformer is at position \#1, the vibration intensity of the monitoring points 1 and 20 all reach the maximum, while that of the point 12 is smaller. It is also the reason that the central location is structurally stable and can transfer most of the energy produced by the vibration directly to the edge location.

\subsubsection{Six-Layer Model}

The six-layer model mainly examines the effect of the propagation of the vibration on the overall structure of the house.

The vibration's propagation law through the whole building will be different from that indoors. Taking the transformer that is at position \#3 as an example, the vibration displacement nephogram is shown in Figure 27 under the condition that the same excitation is applied to the transformer.

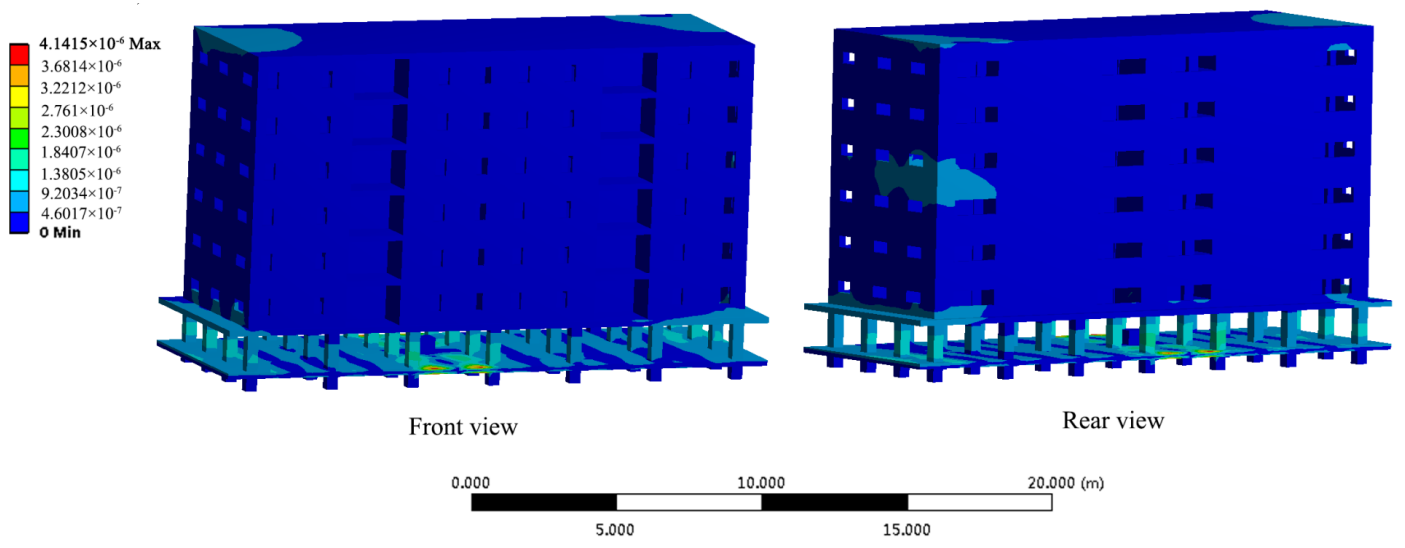

Figure 27. Displacement nephogram of the whole building when transformer is at position \#3.

As can be seen from the Figure 27, the areas that have higher amplitude are near the transformer. The vibration in the basement structure can propagate to the distant areas, and maintain a certain amplitude. It has a large attenuation during the upward transmission, and only affects the boundary region, while having less influence on the central region which is more stable.

In the six-layer model, the monitoring points are set as in Figure 10. ABC represent the three different directions that vibration propagates. A1-A6 represent the six monitoring points of vertical direction, reflecting the propagation law of the vibration along the vertical direction. B1-B8 are eight monitoring points of horizontal direction, reflecting the propagation law of the vibration along the horizontal direction of the building. The $\mathrm{C} 1-\mathrm{C} 3$ three monitoring points are used to reflect the propagation characteristics of the vibration along the longitudinal direction of the building.

The simulation results of the six monitoring points along the vertical direction are shown below in Figure 28, which are basically in accordance with the actual situation. As the story rises, the vibration from the bottom will be gradually weakened. Numerically, when vibration propagates up by a layer, the maximum of the vibration will be reduced by $20 \%$ to $50 \%$ relative to the lower layer. The vibration in the sixth layer is less than $20 \%$ of that in the first layer, so the attenuation in this direction is relatively rapid. 


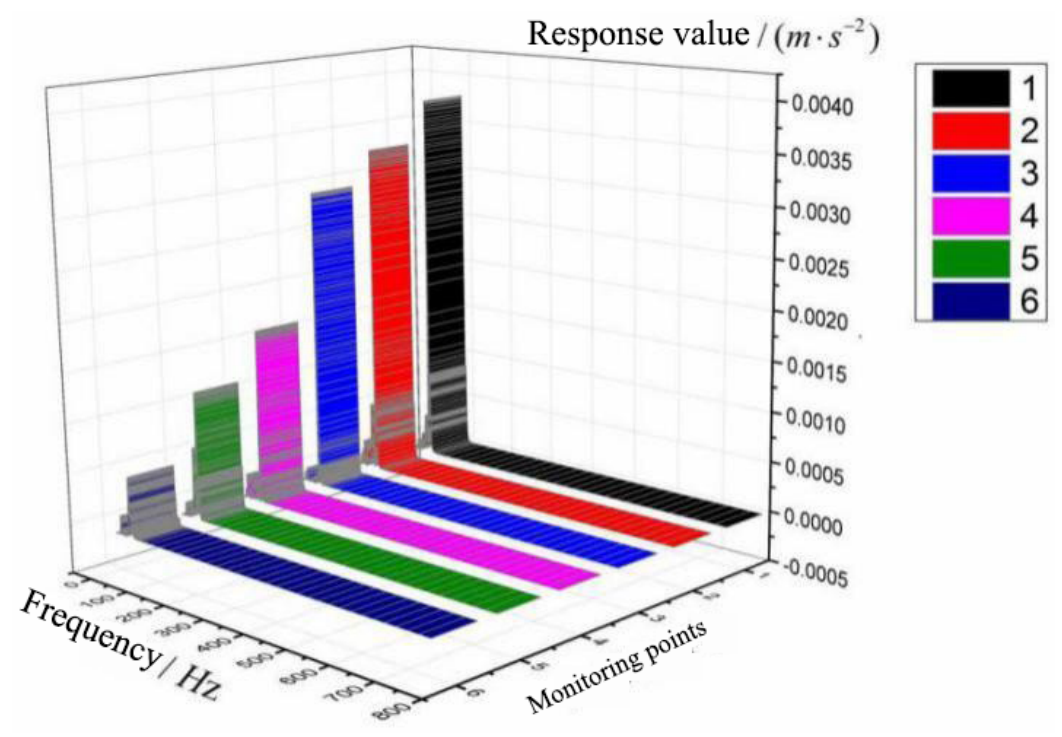

Figure 28. Results of monitoring points A1-A6 when transformer is at position \#3.

The simulation results of the monitoring points B1-B8 of the horizontal direction are shown in Figure 29. It can be seen that in the horizontal direction, the closer to the transformer, the stronger the vibration. The values of the monitoring points 1 , and 2 on the left side are greater than those of the monitoring points 7 , and 8 on the right side. This is because in the model, position \#3 is closer to the left position. There are four unit structures in the horizontal direction and eight monitoring points can be divided into four groups $(1,2),(3,4),(5,6),(7,8)$. There is a wall between each unit structure, which will cause greater attenuation to the vibration. Furthermore, from $(3,4)$ to $(1,2)$, the attenuation of vibration is about $50 \%$, the same as from $(5,6)$ to $(7,8)$.

The simulation results of the monitoring points $\mathrm{C} 1-\mathrm{C} 3$ of the longitudinal direction are shown in Figure 30. In the longitudinal direction, the vibration of the central position is lower than that of both sides. However, the maximum amplitude in this direction is only $30 \%$ of that in the vertical direction, and $75 \%$ of the horizontal direction, relatively the smallest of the three.

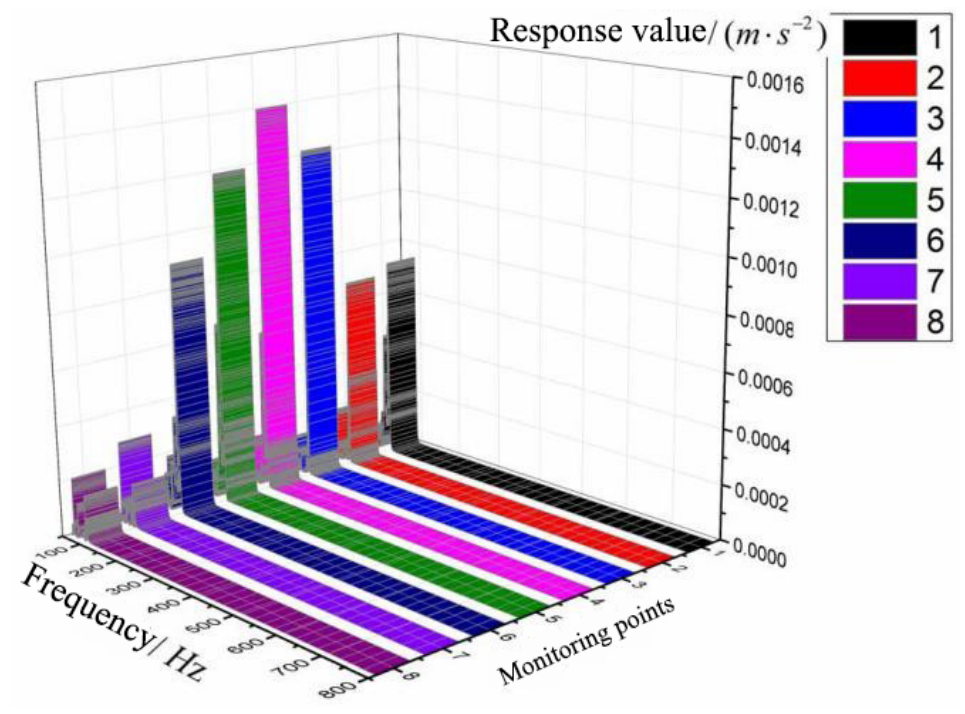

Figure 29. Results of horizontal monitoring points B1-B8 when the transformer is at position \#3. 


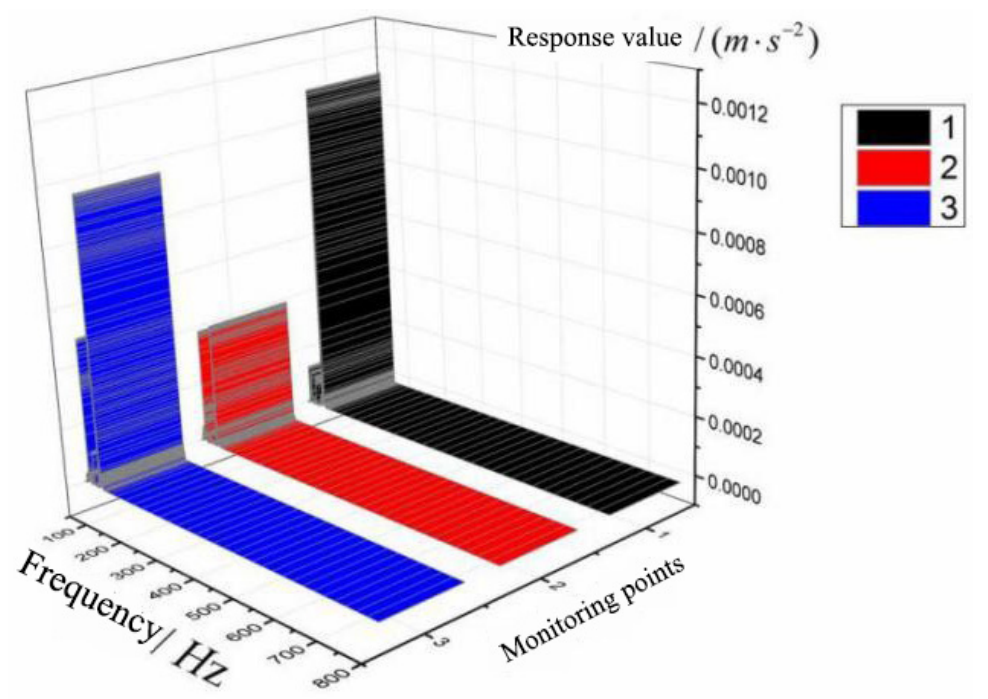

Figure 30. Results of longitudinal monitoring points C1-C3 when the transformer is at position \#3.

When the transformer's position changes, the corresponding vibration intensity will be different. In the six-layer model, situations when the transformer is at positions \#1, \#3, and \#6, are mainly considered. The displacement nephograms are respectively shown in Figures 31 and 32.

Some basic conclusions can be obtained by combining the three displacement nephogram results. When the transformer's position changes, the impact of the vibration on the overall structure of the building will change. Transformer vibration will inevitably have a strong impact on the surroundings, and the place where the vibration is the strongest, is in the transformer-centered small area, changing with the transformer's position. The intensity of the vibration that propagates to the edge will be greater than to the central position. When the transformer is at the edge position, such as position \#6, the impact range of the vibration on the whole wall of the building is larger.

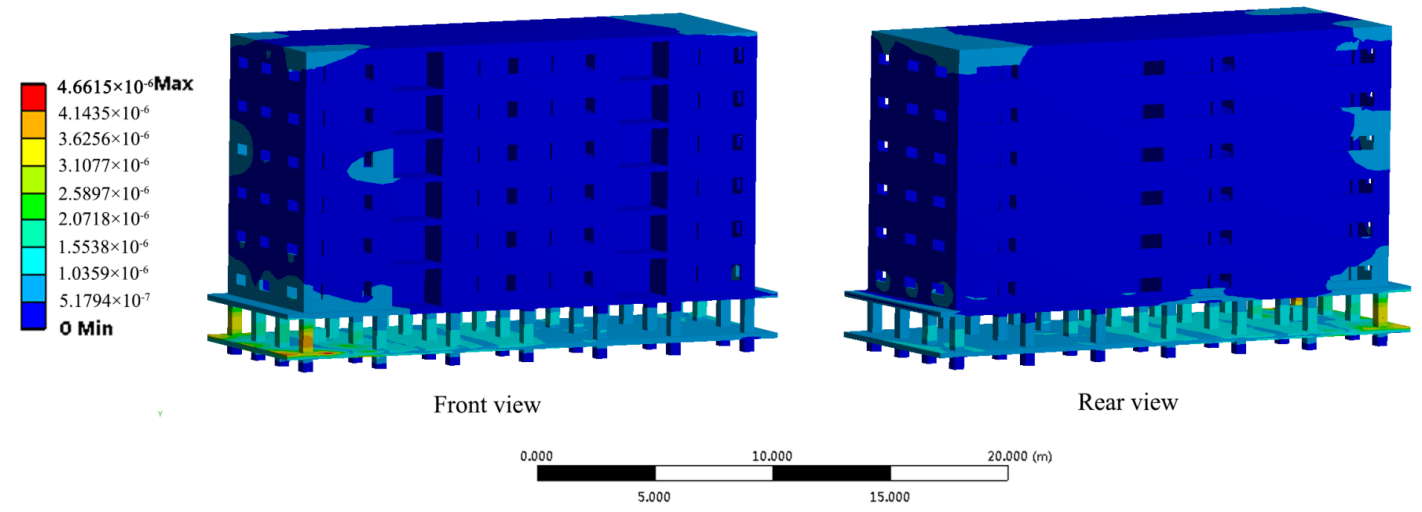

Figure 31. Displacement nephogram of the whole building when the transformer is at position \#1. 


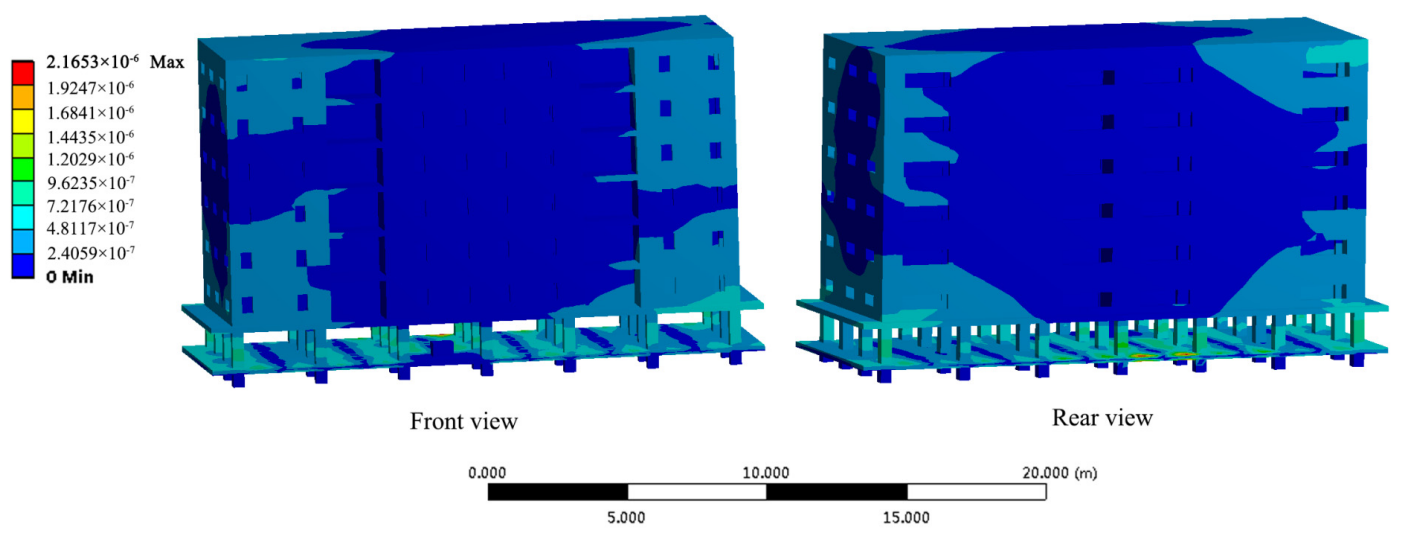

Figure 32. Displacement nephogram of the whole building when the transformer is at position \#6.

Considering the influence caused by different positions of the transformer, specific points in the vertical direction are selected for comparison. The selected 17 points have been simulated and analyzed, here the result of the typical monitoring point 3 is given in Figure 33.

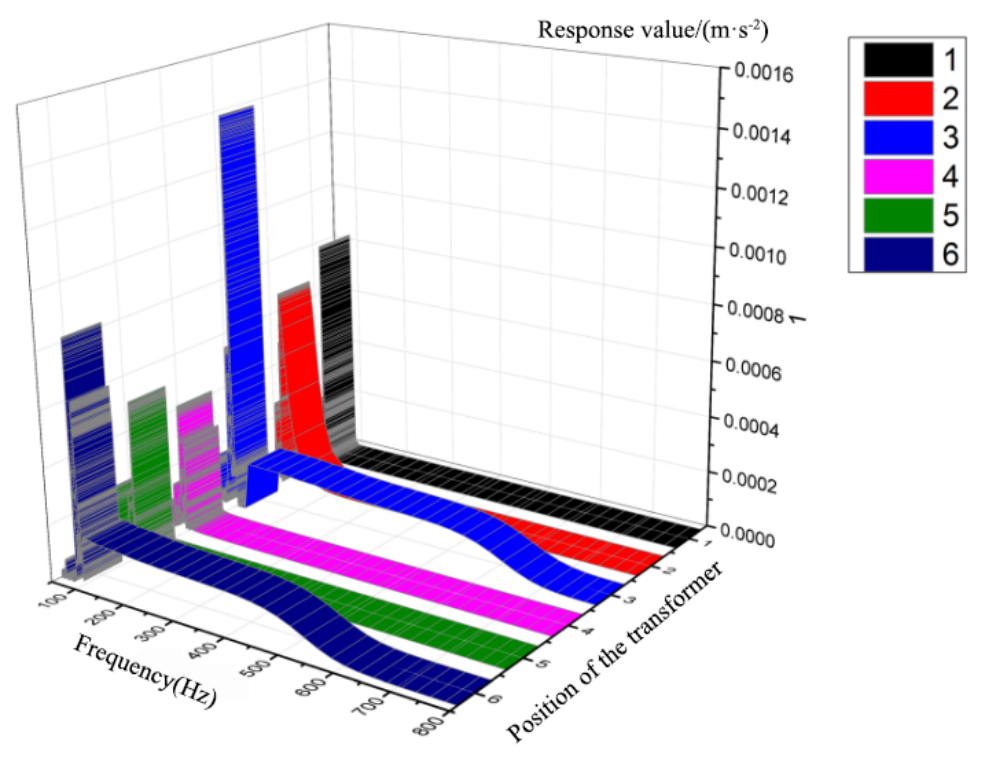

Figure 33. Vibration data of the point 3 when the transformer is at different positions,

From the Figure 33, the closer the transformer is to the monitoring point in the horizontal direction, the stronger the vibration is. By data contrasts between group $(1,4),(2,5),(3,6)$, it can be seen that when the transformer is at the edge, the vibration intensity of the monitoring point is only $50-60 \%$ of that when transformer is at the middle position due to vibration will be transmitted to the edge. Because of it, when the transformer is at central position, its impact range on the whole building is less than that at edge position. From the whole point of view, the best position for the transformer is the central area of the basement.

\section{Structure-Borne Sound Control Method}

From the above simulation results, it is found to be useful to solve the problem of the structure-borne sound caused by the indoor distribution from the vibration source. 


\subsection{Transformer Vibration Isolation}

The vibration generated by the distribution transformer propagates to rooms through structures such as the columns, walls and so on. Although the vibration decays relatively quickly as the story rises, the impact of the vibration on the adjacent room and the lower floors is not negligible. In fact, the transformer's vibration will have little impact on the structure itself but the resulting structural vibration will cause structural noise, which affects the normal life of residents.

If the transformer's noise is only reduced from the perspective of sound insulation, it will only reduce the air noise. This is however powerless for structure-borne sound. Furthermore, some traditional sound absorption and sound insulation materials have limitations on the noise with low frequency range and are prone to resonate, which in return intensify the structure-borne noise [20,21].

Therefore, a comprehensive treatment method perspective should be used for transformer noise pollution. Not only does the sound insulation be adopted, but a reasonable way should also be used to isolate the vibration of the transformer at the same time.

\subsection{Field Test of the Program}

In the field test, installing the vibration absorber base to the transformer is an effective method for reducing the structure-borne sound. Details are shown in the Figure 34.

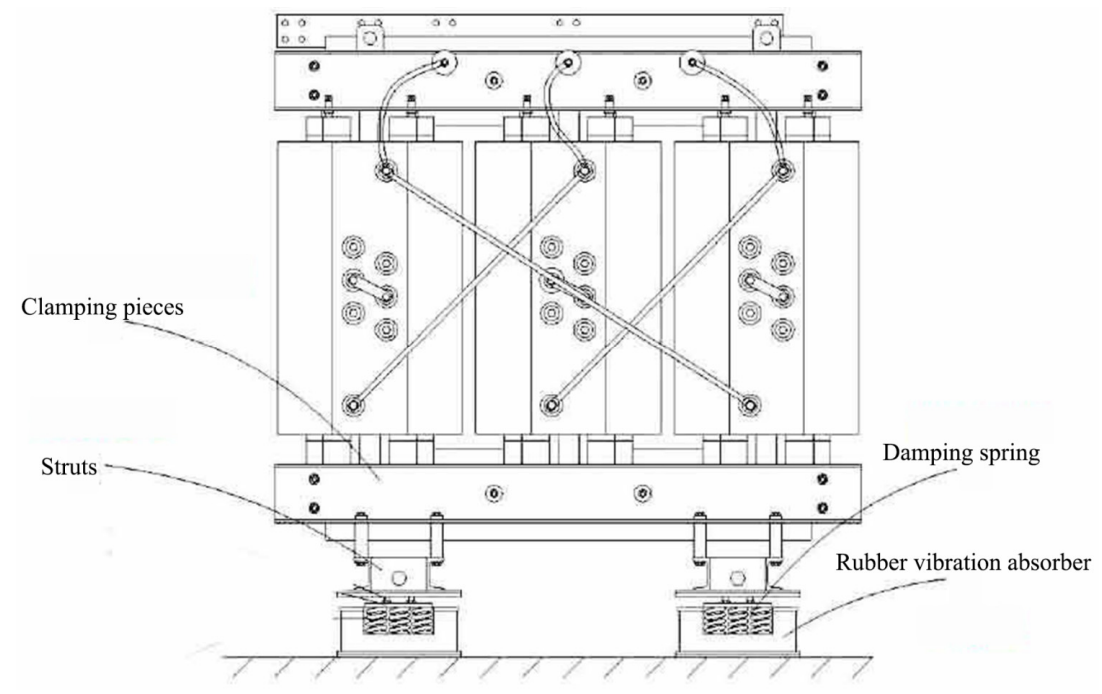

Figure 34. Installation diagram of the vibration absorber base.

The model of the distribution transformer in the field test is SCB11-800/10 as shown in Figures 35 and 36. The distribution transformer is placed in the anechoic chamber, and the probes are placed on the transformer such as the blue oval area in Figure 35 to measure its vibration. Besides, in the anechoic chamber a total of 12 sound sensors are suspended around the room to measure the sound.

The vibration curves of the transformer in three circumstances (no-load, short-circuit, and loaded) are obtained before and after the transformer is installed the vibration absorber base. The results are shown in Figures 37 and 38.

Comparing the results in Figures 37 and 38, in the case with the vibration absorber base, each harmonic component in the spectrum changes greatly, and the fundamental wave is inhibited clearly, basically decreasing by 30-50\%. Although the amplitude of certain higher harmonic components increases a little, from the overall point of view, the inhibition of harmonic components is obvious. This shows the installation of the base will significantly retard the transformer's vibration propagation, thus significantly suppressing the structure-borne noise from the source. 


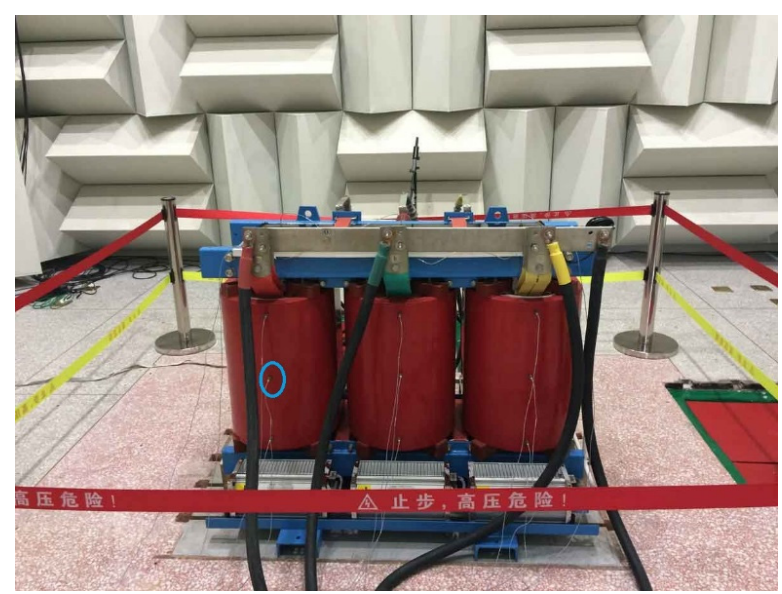

Figure 35. The transformer in the field test.

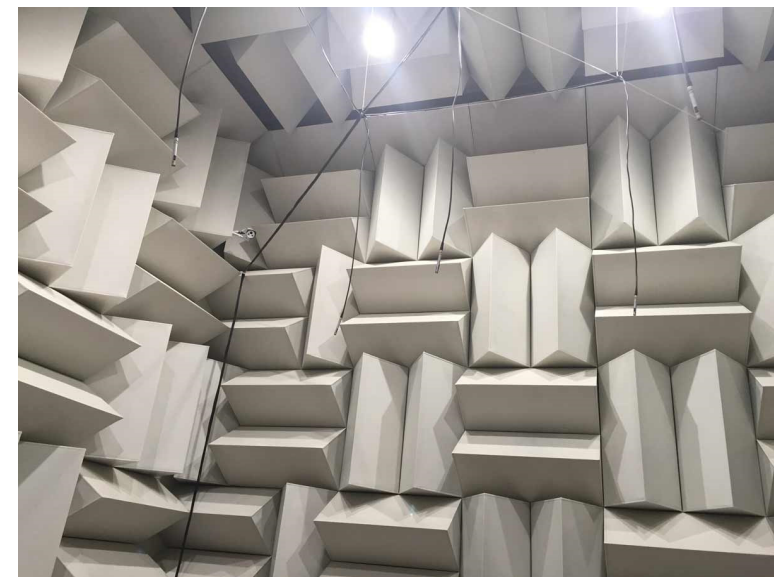

Figure 36. The anechoic chamber and sound sensors.
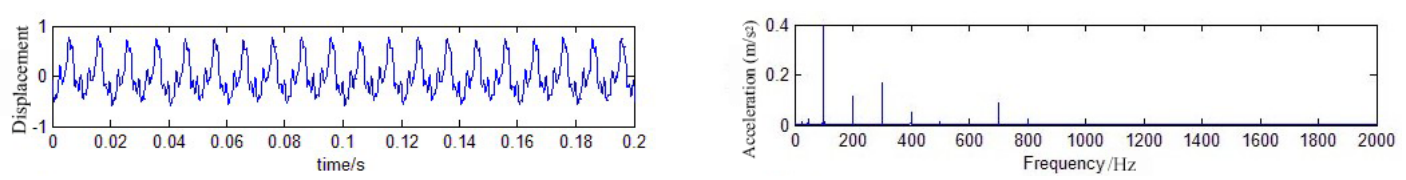

(a)
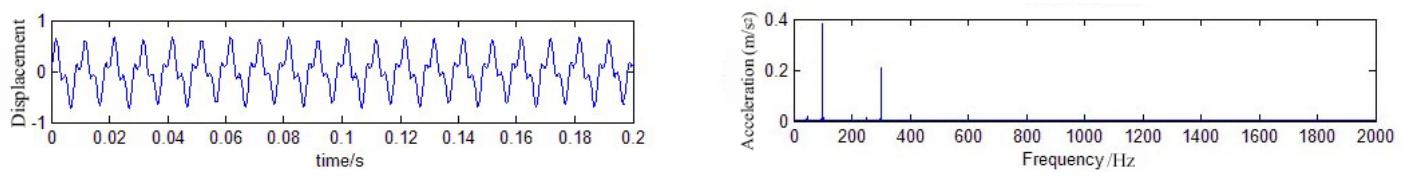

(b)
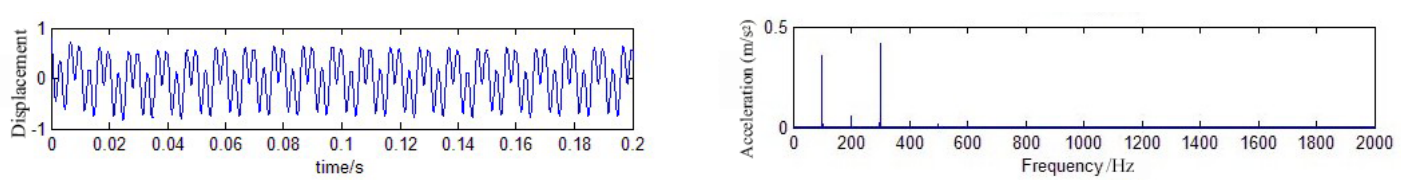

(c)

Figure 37. The measured vibration curves of the coil when the base is not installed: (a) No-load; (b) Short-circuit; (c) Load. 

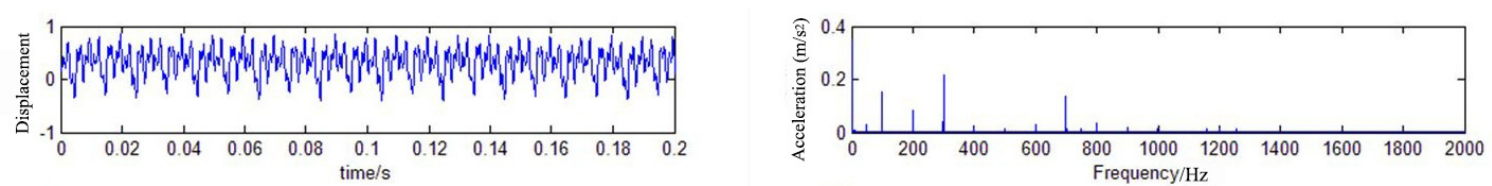

(a)
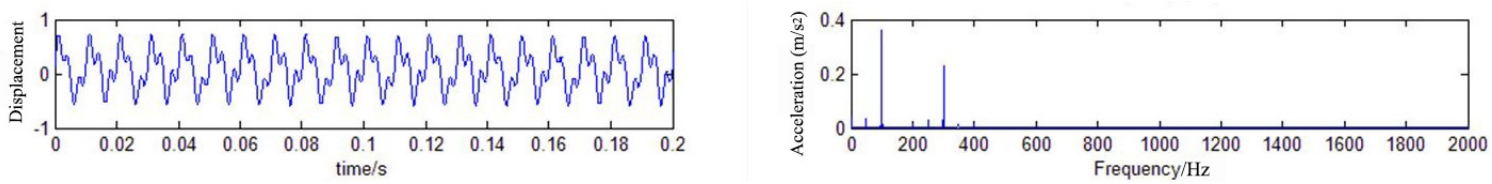

(b)
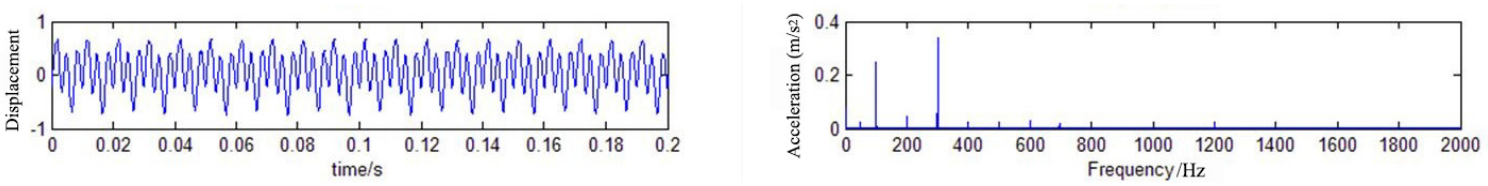

(c)

Figure 38. The measured vibration curves of the coil after the base is installed: (a) No-load; (b) Short-circuit; (c) Load.

\section{Conclusions}

The propagation rule of the structure-borne sound caused by the indoor distribution transformer in a building has been analyzed and the prevention and control method is put forward. The following conclusions can be drawn.

1. Indoors, the vibration propagates mainly upward along columns and beams. The floor structure is relatively stable, while the amplitude of the surrounding walls is relatively large. The vibration of the edge is stronger than that of the center, for the stability of the central structure is higher, and the vibration will be transmitted to the edge. When the transformer is located at the central location, it impacts most on the structure that is right above it and less on the surrounding structure but still cannot be ignored. When the transformer is located at one side edge of the house, it impacts more on all surrounding structures, but much less on the central position.

2. For the whole building, the vibration in the basement structure can propagate to the distant areas, and maintain a certain amplitude. The place where the vibration is strongest is in the transformer-centered small area, changing with the transformer's position. It has large attenuation during upward transmission, and only affects the boundary region, while having less influence on the central region which is more stable.

3. As the story rises, propagating up a layer, the maximum of the vibration of the upper floor will be reduced by $20 \%$ to $50 \%$ relative to the lower layer. Therefore, the attenuation in this direction is relatively rapid. In the horizontal direction, the closer to the transformer, the stronger the vibration is. The attenuation of vibration is about $50 \%$ less through a wall.

4. In the field test, after installing the vibration absorber base to the transformer, each harmonic component in the spectrum changes greatly, and the fundamental wave is inhibited clearly, basically decreasing $30 \%$ to $50 \%$. The installation of the base will significantly suppress the structure-borne noise from the source.

From our perspectives, the best position for the transformer is the central area of the basement for the whole building. However, in the two-layer model, when the transformer is at middle position of the model, the impact of vibration on the upper house is more extensive. From an overall point of view, when the transformer is at the edge position, the impact range of the vibration on the whole wall of 
the building is larger. Therefore, from the scope of the impact on the whole building, we consider that the central area is the best position. Besides, it is useful to control the vibration and structure-borne sound transmission caused by the indoor distribution from the vibration source. It is effective to take vibration isolation measures.

There are still some problems to be further studied in this paper. The vibration propagation models are simplified, only involving two-layer and six-layer house structures, as well as the indoor structure. In addition, in the simulation experiment, only the single transformer is studied, which may be different from the actual situation. When multiple transformers work at the same time, the optimization of the layout and the structure-borne sound propagation laws are worthy of further study.

Acknowledgments: This work was supported in part by the National Natural Science Foundation of China (Grant Number 51507114) and in part by the National Natural Science Foundation of China (Grant Number 51507122).

Author Contributions: Junhua Wang and Yi Xu conceived and designed the simulation; Yi Xu wrote the paper; Kaibin Liang contributed the field test; Qisheng Liu provided the professional guidance; Jiangui Li and Kaipei Liu revised this paper.

Conflicts of Interest: The authors declare no conflict of interest.

\section{References}

1. Escarela-Perez, R.; Kulkarni, S.V.; Melgoza, E. Multi-port network and 3D finite-element models for accurate transformer calculations: Single-phase load-loss test. Electr. Power Syst. Res. 2008, 78, 1941-1945. [CrossRef]

2. Weiser, B.; Pfutzner, H.; Anger, J. Relevance of magnetostriction and forces for the generation of audible noise of transformer cores. IEEE Trans. Magn. 2000, 36, 3759-3777. [CrossRef]

3. Wang, J.; Gao, C.; Duan, X.; Mao, K. Multi-field coupling simulation and experimental study on transformer vibration caused by DC bias. J Electr. Eng. Technol. 2015, 10, 176-187. [CrossRef]

4. Moses, A.J. Measurement of magnetostriction and vibration with regard to transformer noise. IEEE Trans. Magn. 1974, 10, 154-156. [CrossRef]

5. Ertl, M.; Landes, H. Investigation of load noise generation of large power transformer by means of coupled 3D FEM analysis. COMPEL 2007, 26, 788-799. [CrossRef]

6. Moses, A.J.; Anderson, P.I.; Phophongviwat, T.; Tabrizi, S. Contribution of magnetostriction to transformer noise. In Proceedings of the 2010 45th International on Universities Power Engineering Conference, Cardiff, UK, 31 August-3 September 2010; pp. 1-5.

7. Ming, R.S.; Pan, J.; Norton, M.P.; Wende, S.; Huang, H. The sound-field characterisation of a power transformer. Appl. Acoust. 1999, 56, 257-272. [CrossRef]

8. Doggett, F. Transformers in the built environment. J. Acoust. Soc. Am. 2015, 137, 2319. [CrossRef]

9. Gibbs, B.M. Uncertainties in predicting structure-borne sound power input into buildings. J. Acoust. Soc. Am. 2013, 133, 2678-2689. [CrossRef] [PubMed]

10. Steel, J.A.; Craik, R. Statistical energy analysis of structure-borne sound transmission by finite element methods. J. Sound Vib. 1994, 178, 553-561. [CrossRef]

11. Craik, R.; Smith, R.S. Sound transmission through lightweight parallel plates. Part II: Structure-borne sound. Appl. Acoust. 2000, 61, 247-269. [CrossRef]

12. Yamazaki, T.; Kuroda, K.; Mori, A. A structural design process for reducing structure-borne sound on machinery using SEA (mechanical systems). Trans. Jpn. Soc. Mech. Eng. 2007, 73, 446-452. [CrossRef]

13. Toyoda, M.; Takahashi, D. Prediction for architectural structure-borne sound by the finite-difference time-domain method. Acoust. Sci. Technol. 2009, 30, 265-276. [CrossRef]

14. Mandal, N.K.; Leong, M.S.; Abd Rahman, R. Prediction of structure-borne sound in orthotropic plates for far-field conditions. J. Vib. Control. 2002, 8, 3-12. [CrossRef]

15. Magalhaes, M.D.C. Quantification of structure-borne sound transmission in buildings. In Proceedings of the 17th International Congress on Sound and Vibration, Cairo, Egypt, 18-22 July 2010; pp. 825-831.

16. Magalhaes, M.; Ferguson, N.S. The development of a Component Mode Synthesis (CMS) model for three-dimensional fluid-structure interaction. J. Acoust. Soc. Am. 2005, 118, 3679-3690. [CrossRef]

17. Sanayei, M.; Kayiparambil, A.P.; Moore, J.A.; Brett, C.R. Measurement and prediction of train-induced vibrations in a full-scale building. Eng. Struct. 2014, 77, 119-128. [CrossRef] 
18. Moorhouse, A.; Elliott, A.; Eastwick, G.; Evans, T.; Ryan, A.; von Hunerbein, S.; Le Bescond, V.; Waddington, D. Structure-borne sound and vibration from building-mounted wind turbines. Environ. Res. Lett. 2011, 6, 035102. [CrossRef]

19. Hong, K.; Pan, Z. Vibration model of power transformer under short-circuit condition. In Proceedings of the International Conference on Electrical Machines and Systems ICEMS, Tokyo, Japan, 15-18 November 2009; pp. 1234-1238.

20. Kanoi, M.; Hori, Y.; Maejima, M.; Obata, T. Transformer noise reduction with new sound insulation panel. IEEE Trans. Power Appar. Syst. 1983, 102, 2817-2825. [CrossRef]

21. Zhang, X.; Duan, S.; Cao, M.; Mo, J.; Sun, Y.; Guo, Y.; He, G. Design of transformer substation low frequency sound absorber and test study on sound absorption property. Appl. Mech. Mater. 2014, 468, 134-140. [CrossRef]

(c) (1) BY

(c) 2017 by the authors. Licensee MDPI, Basel, Switzerland. This article is an open access article distributed under the terms and conditions of the Creative Commons Attribution (CC BY) license (http:/ / creativecommons.org/licenses/by/4.0/). 